\title{
Application of Box-Behnken Experimental Design for the Formulation and Optimisation of Selenomethionine-Loaded Chitosan Nanoparticles Coated with Zein for Oral Delivery.
}

\author{
Giuliana Vozza \\ Technological University Dublin \\ Minna Danish \\ Technological University Dublin \\ Hugh J. Byrne \\ Technological University Dublin, hugh.byrne@tudublin.ie
}

See next page for additional authors

Follow this and additional works at: https://arrow.tudublin.ie/nanolart

Part of the Physics Commons

\section{Recommended Citation}

Ryan, S. et al. (2018) Application of Box-Behnken Experimental Design for the Formulation and Optimisation of Selenomethionine-Loaded Chitosan Nanoparticles Coated with Zein for Oral Delivery, Int J Pharm.2018 Nov 15;551(1-2):257-269. doi:10.1016/j.ijpharm.2018.08.050

This Article is brought to you for free and open access by the NanoLab at ARROW@TU Dublin. It has been accepted for inclusion in Articles by an authorized administrator of ARROW@TU Dublin. For more information, please contact arrow.admin@tudublin.ie, aisling.coyne@tudublin.ie,gerard.connolly@tudublin.ie.

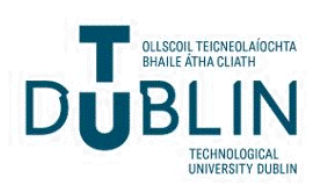


Authors

Giuliana Vozza, Minna Danish, Hugh J. Byrne, Jesus Maria Frias, and Sinéad M. Ryan

This article is available at ARROW@TU Dublin: https://arrow.tudublin.ie/nanolart/89 
1 Application of Box-Behnken experimental design for the formulation and

2 optimisation of selenomethionine-loaded chitosan nanoparticles coated with

3 zein for oral delivery

4

5 Giuliana Vozza $^{\mathrm{a} b}$, Minna Danish ${ }^{\mathrm{a} b}$, Hugh J. Byrne ${ }^{\mathrm{b}}$, Jesús M. Frías ${ }^{\mathrm{c}}$, Sinéad M. Ryan ${ }^{\mathrm{d},{ }^{*}}$

$6{ }^{a}$ School of Food Science and Environmental Health, Dublin Institute of Technology,

7 Marlborough Street, Dublin 1, Ireland

$8{ }^{\mathrm{b}}$ FOCAS Research Institute, Dublin Institute of Technology, Kevin Street, Dublin 8, Ireland

$9{ }^{\mathrm{c}}$ Environmental Science and Health Institute, Dublin Institute of Technology, Grangegorman,

10 d, School of Veterinary Medicine, University College Dublin, Belfield, Dublin 4, Ireland

11 Dublin 7, Ireland

$12{ }^{*}$ Corresponding author. E-mail: Sinead.Ryan@ucd.ie

13

14

15

16

17

18

19

20

21

22

23

24

25 


\section{Abstract:}

27 Selenomethionine is an essential amino acid with a narrow therapeutic index and susceptibility to oxidation. Here it was encapsulated into a nanoparticle composed of chitosan cross-linked with tripolyphosphate for oral delivery. The formulation was optimised using a three-factor Box-Behnken experimental design. The chitosan:tripolyphosphate ratio, chitosan

31 solvent $\mathrm{pH}$, and drug load concentration were independently varied. The dependent variables studied were encapsulation efficiency, particle size, polydispersity index and zeta potential. For optimisation, encapsulation efficiency and zeta potential were maximised, particle diameter was set to $300 \mathrm{~nm}$ and polydispersity index was minimised. A $0.15 \mathrm{mg} / \mathrm{mL}$ concentration of selenomethionine, chitosan solvent $\mathrm{pH}$ of 3 , and chitosan:tripolyphosphate ratio of 6:1 yielded optimum nanoparticles of size $187 \pm 58 \mathrm{~nm}$, polydispersity index $0.24 \pm 0.01$, zeta potential $36 \pm 6 \mathrm{mV}$, and encapsulation efficiency of $39 \pm 3 \%$. Encapsulation efficiency was doubled to $80 \pm 1.5 \%$ by varying $\mathrm{pH}$ of the ionotropic solution components and by subsequent coating of the NPs with zein, increasing NP diameter to $377 \pm 47 \mathrm{~nm}$, whilst retaining polydispersity index and zeta potential values. Selenomethionine-entrapped nanoparticles were not cytotoxic to intestinal and liver cell lines. Accelerated thermal stability studies indicated good stability of the nanoparticles under normal storage conditions $\left(23^{\circ} \mathrm{C}\right)$. In simulated gastrointestinal and intestinal fluid conditions, $60 \%$ cumulative release was obtained over 6 hours.

\section{Keywords:}




\section{Abbreviations}

54 BBD, Box-Behnken design; CL113, PROTASANTM UP; Cs, Chitosan; DLS, dynamic light scattering; EE\%, Encapsulation efficiency; GRAS, Generally recognised as safe; LDV, laser doppler velocimetry; MSC, methylselenocysteine; NP, nanoparticle; PDI, Polydispersity; pI, Isoelectric point; SeCys, selenocysteine; SeMet, Selenomethionine; TPP, Tripolyphosphate; $\mathbf{Z P}$, Zeta potential.

\section{INTRODUCTION}

Selenium is an essential micronutrient in human and animal nutrition (Rayman, 2000), that exists in a wide array of different formats, both organic and inorganic, better known as speciation. Selenomethionine (SeMet), the selenium analogue of methionine, is the predominant form of organic Se found in foods from the Brassica and Allium families (Reilly et al., 2014). SeMet is used for oral supplementation due to its capacity to be non-specifically incorporated into body proteins in place of methionine (Rayman et al., 2008). The potential health benefits of selenium are dependent on its chemical species, and several studies have suggested a possible role in cancer prevention (Nie et al., 2016), increased immunological status (Narayan et al., 2015) and increased fertility (Shanmugam et al., 2015). SeMet may also to have a number of benefits regarding oncology treatments due to its modulation of the therapeutic efficacy and selectivity of anticancer drugs (Evans et al., 2017), capacity to provide protection of normal tissues from the toxicities associated with chemotherapy and radiation treatments, in addition to enhancing their anti-tumour effects (Chintala et al., 2012;

73 Mix et al., 2015; Panchuk et al., 2016). It may also have some potential in degenerative disease by decreasing oxidative stress of small molecule antioxidants used as a buffer for free 
radicals in brain tissue (Reddy et al., 2017; Song et al., 2014). However, the oral delivery of SeMet can be challenging due to the distinctive electronegativity and atomic radius of the selenium atom (i.e. larger radius and lower electronegativity than sulphur,) that makes it easier for low valence state Se compounds to be more readily oxidised compared to their sulphur counter parts (Xu et al., 2013). SeMet is readily oxidised (Davies, 2016) and, even though it is less toxic than inorganic selenium (Se), it still has a low therapeutic index (Takahashi et al., 2017). Oral delivery formulations of SeMet therefore need to consider the balance between doses that exert beneficial effects and those which may potentially be toxic.

Inorganic Se species such as selenite $\left(\mathrm{SeO}_{3}{ }^{2-}\right)$ and elemental selenium $\left(\mathrm{Se}_{0}\right)$, together with methylseleninic acid, have been formulated to nano-enabled delivery systems which exhibited improved bioactivity with reduced cytotoxicity in vitro (Forootanfar et al., 2014; Loeschner et al., 2014; Zhang et al., 2008). Nanoparticles (NPs) can be more biologically active due to their enhanced surface area per mass compared with larger-sized particles of the same chemistry (Oberdörster et al., 2005). By using NPs as a drug delivery vehicle, it might be possible to enhance a range of characteristics for a given bioactive, including; increased protection and stability (Nair et al., 2010) and suitability to increase bioavailability by nonparenteral routes of administration including oral, pulmonary and topical applications (Helson, 2013).

The natural polymer chitosan (Cs) is a mucopolysaccharide, closely related to cellulose and obtained by deacetylation of the compound chitin, predominantly found in the exoskeletons of crustaceans (Nagpal et al., 2010). Cs has been used for the development and formulation of nanoparticles by ionotropic gelation due to its physicochemical and biological beneficial properties (Mohammed et al., 2017; H. Zhang et al., 2015). Benefits include improved 
adherence to mucosal surfaces, increased drug residence time (Ryan et al., 2012), and protection of the bioactive drug from intestinal proteases (Amaro et al., 2015; Ryan et al., 2013). In acidic medium, Cs can be dissolved, due to protonation of the amine residues present in the polymer backbone. Ionotropic gelation allows for the formation of NPs from

104 Cs via crosslinking with oppositely-charged electrolytes under mild conditions in which amino acids and peptides will remain reasonably stable (Chen et al., 2013; Janes et al., 2001; Wang et al., 2011).

Zein a GRAS approved prolamine-rich protein derived from maize, has been used in the

109 formulation and coating of peptide oral delivery systems (Y. Zhang et al., 2015), to increase

110 encapsulation efficiency (Luo and Wang, 2014) and improve the control of gastric release of

111 labile bioactives (Luo et al., 2010; Paliwal and Palakurthi, 2014). By exploiting the physical

112 interactions between protein and polysaccharide (in this instance zein and Cs), it is possible

113 to improve and broaden the physical and chemical stability properties of the NP delivery

114 systems (Benshitrit et al., 2012). However, the formulation, characterisation and development

115 of these multi-component systems can be more challenging than single component systems

116 and as such, it is important to comprehensively optimise the formulation process. To the best

117 of our knowledge, there are currently no reports which describe the formulation of biological

118 Se species such as SeMet into a NP delivery system. The potential optimisation of this

119 formulation could be significant, given that SeMet more effectively increases human and

120 animal selenium levels and is less toxic than inorganic Se (Garousi, 2015).

122 In situations where several variables may influence system properties, a useful technique to

123 identify the relationships between a given response and independent variables (or factors) and 124 optimise the system, is Response Surface Methodology (RSM) (Anderson and Whitcomb, 
125 2005). RSM is a more efficient approach to experimentation than one factor at a time (OFAT)

126 experiments since it: 1 ) reduces the number of experimental runs typically required to gather

127 the same information as OFAT, thus reducing resource requirements, 2) is useful in detecting

128 interdependencies of variables that would not be typically identified during OFAT

129 experiments and 3) improves the prediction of a response through use of gathered

130 information from a larger parameter space. One of the most commonly applied RSM designs

131 for process optimisation with a minimal experimental requirement is the Box-Benhken design

132 (BBD), an independent quadratic design in which factor combinations are considered at 3

133 levels; the midpoints of edges of the process space and the centre (Traynor et al., 2013;

134 Zolgharnein et al., 2013). After polynomial models for each of the different responses in a

135 study have been completed, a desirability function may be constructed in order to estimate

136 minima or maxima, provided such optima are within the design space (Bezerra et al., 2008).

138 In this study, SeMet was formulated into nanoparticles consisting of Cs and zein using

139 ionotropic gelation. After evaluating the main variables which affect encapsulation

140 efficiency, particle size and drug loading, a systematic approach (RSM) was used to optimise

141 the formulation of nanoparticles suitable for oral delivery. A three-level, three-factor BBD

142 was utilised to build polynomial models for the three responses and a desirability function

143 was then constructed to optimise the system. Optimised SeMet NPs were prepared based on

144 the predicted optimum levels of the independent variables of the factorial design. To ensure

145 stability of the optimised formulation after lyophilisation, a cryoprotectant (trehalose) was

146 also included (Danish et al., 2017a). The physicochemical properties, storage stability,

147 cytotoxicity, and the release profile in a simulated intestinal buffer were assessed.

\section{MATERIALS AND METHODS}




\subsection{Materials}

150 The chitosan ultrapure PROTASAN"M UP (CL113, Mw=110-150kDa, DDA=85\%,

151 Endotoxins $\leq 100$ EU/gram, Heavy metals $\leq 40$ ppm) was purchased from NovaMatrix, FMC

152 Corporations, Norway. DL-selenomethionine, $\mathrm{D}(+)$-Trehalose dihydrate, and zein, of $\geq 99 \%$

153 purity, were obtained from ACROS Organics ${ }^{\mathrm{TM}}$, Fisher Scientific, Ireland. Ultra-pure water

$15418 \mathrm{~m} \Omega \mathrm{cm}^{-1}$ was obtained from a Millipore simplicity 185 model instrument, UK, and was

155 used for all aqueous solution preparations throughout. Sodium Tripolyphosphate (TPP) of

156 technical grade (85\%), and all other reagents, chemicals and solvents were of analytical grade

157 from Sigma Aldrich, Ireland.

$158 \quad 2.2$ Optimisation of nanoparticle formulation physicochemical properties

159 A BBD was used to optimise the formulation and EE\% of SeMet into the nanoparticle.

160 Selected target physicochemical properties for oral delivery for the NPs were particle size of

161 approximately $300 \mathrm{~nm}, \mathrm{PDI}<0.5$ and ZP > $30 \mathrm{mV}$ (des Rieux et al., 2006). A three level,

162 three factor BBD (Maleki Dizaj et al., 2015; Zhao et al., 2013) of 15 random order

163 experiments was designed using Minitab ${ }^{\mathrm{TM}} 17$ (Pennsylvania, USA). The 3 independent

164 variables were, $\left(\mathrm{X}_{1}\right)$ the $\mathrm{pH}$ of the Cs solvent - the isoelectric point $(\mathrm{pI})$ of SeMet, $(\mathrm{pH}-\mathrm{pI})$

$165\left(\mathrm{X}_{2}\right)$, the load concentration of SeMet and $\left(\mathrm{X}_{3}\right)$ the ratio of Cs:TPP, while $\left(\mathrm{Y}_{1}\right)$ Particle size,

$166\left(\mathrm{Y}_{2}\right) \mathrm{PDI},\left(\mathrm{Y}_{3}\right) \mathrm{ZP}$ and $\left(\mathrm{Y}_{4}\right)$ EE\% were the dependent variables. The variable ranges (Table

167 1) were based on an exploratory study.

168 Each dependant variable was independently assessed by linear regression using a $2^{\text {nd }}$ degree 169 polynomial model with $1^{\text {st }}$ order interactions (Eq. 1).

170

171

$$
\mathbf{Y}_{\mathbf{i}}=\mathbf{b}_{0}+\mathbf{b}_{1} \mathbf{X}_{1}+\mathbf{b}_{2} \mathbf{X}_{2}+\mathbf{b}_{3} \mathbf{X}_{3}+\mathbf{b}_{12} \mathbf{X}_{1} \mathbf{X}_{2}+\mathbf{b}_{13} \mathbf{X}_{1} \mathbf{X}_{3}+\mathbf{b}_{23} \mathbf{X}_{2} \mathbf{X}_{3}+\mathbf{b}_{11} \mathbf{X}_{1}{ }^{2}+\mathbf{b}_{22} \mathbf{X}_{2}{ }^{2}+\mathbf{b}_{33} \mathbf{X}_{3}{ }^{2}+\varepsilon
$$

(Eq. 1) 
173 where $Y_{i}$ is the measure of the response associated with each factor level combination, $b_{0}$ is

174 an intercept, $b_{1}-b_{33}$ are the regression coefficients, $X_{1}-X_{3}$ are the coded independent variables

175 and the $\mathrm{X}_{\mathrm{i}} \mathrm{X}_{\mathrm{j}}$ and $\mathrm{X}_{\mathrm{i}}^{2}(\mathrm{i}, \mathrm{j}=1,2,3)$ denote the interactive and quadratic terms, respectively. The

176 linear regression and the significance $(\mathrm{p}<0.05)$ test of independent variables and their

177 interactions was assessed by statistical software (Minitab $\left.{ }^{\mathrm{TM}}, 17\right)$ to generate regression

178 models. Through bidirectional elimination (testing at each step for variables to be included or

179 excluded), non-significant terms were removed from the model in order to calculate

180 regression equations with significant terms only (Wang et al., 2013). Desirability functions

181 to optimise all responses were built the weighted geometric mean of individual desirabilities

182 presented in Table 1.

183

184

Table 1: Variables and levels employed in the BBD with desirability function for optimisation of nanoparticle formulation.

\begin{tabular}{|l|l|l|l|}
\hline \multirow{2}{*}{ Factor (Independent variables) } & \multicolumn{3}{|l|}{ Levels used, (Actual coded) } \\
\hline $\mathrm{X}_{1}=\mathrm{pH}$ of the Cs solvent - the pI of SeMet (pH- $\left.\mathrm{pI}\right)$ & 0.5 & 1.5 & 2.5 \\
\hline $\mathrm{X}_{2}=$ SeMet concentration $(\mathrm{mg} / \mathrm{mL})$ & 0.05 & 0.15 & 0.25 \\
\hline $\mathrm{X}_{3}=$ ratio of Cs:TPP & $4: 1$ & $6: 1$ & $8: 1$ \\
\hline Dependent Variables & \multicolumn{3}{|l|}{ Composite desirability } \\
\hline $\mathrm{Y}_{1}=$ Size $(\mathrm{nm})$ & Target of 300nm \\
\hline $\mathrm{Y}_{2}=$ PDI & Minimise \\
\hline $\mathrm{Y}_{3}=\mathrm{ZP}(\mathrm{mV})$ & Maximise \\
\hline $\mathrm{Y}_{4}=$ Encapsulation efficiency (EE\%) & Maximise \\
\hline
\end{tabular}

186

187 Response surface plots, statistical testing of the linear models and identification of optimum

188 formulations via feasibility and grid searches was performed to study the optimal area

189 (Barrentine, 1999). Finally, repetitions $(\mathrm{N}=4)$ of the optimal point found were conducted experimentally to validate the study. 


\subsection{Preparation of SeMet loaded Cs:TPP nanoparticles}

192

193

194

195

196

197

198

199

200

201

202

203

204

205

206

207

208

209

210

211

212

213

214

215

SeMet-entrapped NPs were produced using a modified ionic gelation method (Calvo et al., 1997). Briefly, Cs was dissolved in buffered $\mathrm{pH}$ medium $(3,4$ or $5 \mathrm{pH})$ at a concentration of $3 \mathrm{mg} / \mathrm{mL}$ and filtered through a $0.22 \mu \mathrm{m}$ syringe filter (Millex Millipore, UK) to remove undissolved Cs. A known amount of SeMet was then added to the Cs solution prior to crosslinking to obtain a final load concentration $0.05,0.150$ or $0.250 \mathrm{mg} / \mathrm{mL}$. TPP was added dropwise to the solution under stirring at $700 \mathrm{rpm}$ and room temperature to yield final mass ratios of Cs:TPP NPs of 4:1, 6:1 and 8:1. All of these experimental parameters $(\mathrm{pH}$, concentrations and ratios) were prepared according to the BBD design. The NP suspension was stirred at $700 \mathrm{rpm}$ for $30 \mathrm{~min}$ at room temperature for further crosslinking. After stabilisation, NPs were then transferred to a $30 \mathrm{kDa}$ molecular weight cut off (Vivaspin 20, Sartorius) centrifugal filter and isolated by centrifugation at $3000 \mathrm{rpm}$ for $30 \mathrm{~min}$. Filtered $\mathrm{H}_{2} \mathrm{O}$ (equivalent in volume to the recovered supernatant) was then added to the isolated NPs and sonicated at $35 \%$ amplitude for 30 s with 5 s pulse intervals. Physicochemical properties of the NPs were then determined as per section 2.4, using a Malvern Zetasizer NanoZS (Worcestershire, UK) and the supernatant was retained for EE\% determination as outlined in section 2.7. The optimised formulation has a mass ratio 6:1 (Cs:TPP), Cs media (pH 5), and a final SeMet load concentration of $0.15 \mathrm{mg} / \mathrm{mL}$.

\subsubsection{Increase of Ionisation/Protonation states of NP components during ionic gelation to} increase EE\% - Formulation I

After optimising the general physicochemical properties via BBD (section 2.2), the ionic gelation component preparation procedure was modified with the aim of increasing the EE \%. Formulation I was produced as described in section 2.3 with one exception; SeMet and TPP were dissolved and diluted with $\mathrm{NaOH}(0.01 \mathrm{M})$ prior to crosslinking. The rationale for the $\mathrm{pH}$ adjustment was to induce higher electrostatic interactions (i.e. maximise the cationic 
component of Cs and the anionic component of SeMet) between SeMet and Cs during the crosslinking process.

\section{2.3.2 Coating NPs with zein to increase EE\%}

219 NPs were prepared as per formulation I (ratio 6:1 (Cs:TPP), Cs media (pH 3), TPP/SeMet

$220 \mathrm{NaOH}$ solution ( $\mathrm{pH} 11$ ) and a final load concentration of $0.15 \mathrm{mg} / \mathrm{mL}$ ), with the following modifications; after the NPs had stabilised, $8 \mathrm{~mL}$ of absolute EtOH were added dropwise to the formulation whilst the stirring speed of the solution was maintained at $700 \mathrm{rpm}$ for $30 \mathrm{~min}$ at room temperature. Zein (10 mg/mL dissolved in $80 \% \mathrm{EtOH}$ and filtered) was added dropwise to yield zein:Cs mass ratios of $0.5: 1,1: 1$ and 2:1, stabilised at $700 \mathrm{rpm}$ for $30 \mathrm{~min}$ and isolated as per section 2.3. The NP formulations were then concentrated under vacuum (175 mbar) at $40^{\circ} \mathrm{C}$ until EtOH was completely removed. To ensure stability of the optimised formulation after lyophilisation, $10 \mathrm{~mL}$ of the cryoprotectant trehalose $5 \% \mathrm{w} / \mathrm{v}$ in $\mathrm{H}_{2} \mathrm{O}$ was added to each formulation and lyophilised for $36 \mathrm{hr}$ (Danish et al., 2017a).

\subsection{Nanoparticle Characterisation: Particle size, PDI and surface charge}

Freshly prepared NP solutions were used for physicochemical analysis (Luo et al., 2010). The mean particle size and PDI of the NP formulations were determined by dynamic light scattering (DLS). The ZP values were measured with the use of laser doppler velocimetry

234 (LDV). Both DLS and LDV analysis were performed in triplicate at $25^{\circ} \mathrm{C}$ with a Zetasizer

235 Nano series Nano-ZS ZEN3600 fitted with a 633 nm laser (Malvern Instruments Ltd., UK), using a folded capillary cuvette (Folded capillary cell-DTS1060, Malvern, UK). The values presented herein were acquired from three separate experiments, each of which included three replicates; $\mathrm{N}=3$. 


\subsection{Scanning electron microscopy (SEM)}

240 NP morphology was evaluated by scanning electron microscopy (SEM) (Hitachi, SU6600 FESEM, USA), at an accelerating voltage of $20 \mathrm{kV}$, unless otherwise stated, using the secondary electron detector. The fresh NP solutions were then spin coated onto Si wafers,

243 dried at room temperature and then sputter coated with $4 \mathrm{~nm} \mathrm{Au} / \mathrm{Pd}$ prior to imaging

244 (Mukhopadhyay et al., 2013).

\subsection{Fourier transform infrared spectroscopy (FTIR)}

FTIR spectra of CL113, TPP, Cs:TPP NPs, SeMet and SeMet loaded Cs:TPP NPs were acquired via a Spotlight 400 series spectrometer (Perkin Elmer, USA), using the attenuated total reflectance spectroscopy method (ATR-FTIR), in the range of $650-4000 \mathrm{~cm}^{-1}$. Prior to analysis, NP samples were lyophilised using a FreeZone 6 L bench top freeze dry system (Labconco, USA) at $-40{ }^{\circ} \mathrm{C}$ for $20 \mathrm{hr}$. The dried solids were then placed on the ATR crystal prism (ZnSe), and 32 scans were acquired at $4 \mathrm{~cm}^{-1}$ resolution with background subtraction using the empty sample holder (Vongchan et al., 2011).

\subsection{EE\% of SeMet in Cs:TPP nanoparticles}

254 The EE\% of SeMet in the NPs was determined by the separation and quantification of SeMet 255 left in the supernatant. This was performed by ultracentrifugation at $3000 \mathrm{rpm}, 4^{\circ} \mathrm{C}$ for 30 min. SeMet in the supernatant was quantified by reverse phase high performance liquid chromatography (RP-HPLC), as previously described (Ward et al., 2012) with the following modifications. Samples were analysed with a Waters 2998 HPLC and Photodiode Array

259 Detector, (Waters, USA), using a Poroshell 120, EC-C8 column, $3.0 \times 100 \mathrm{~mm}, 2.7 \mu \mathrm{m}$, 260 (Agilent Technologies, UK). Isocratic elution was carried out at a flow rate of $0.4 \mathrm{~mL} / \mathrm{min}$, 
262 (97.9:2.0:0.1). Samples were monitored according to their UV absorbance at $218 \mathrm{~nm}$. The encapsulation efficiency was calculated by Eq. 2 (Xu and Du, 2003);

264

265

$E E \%=\frac{\text { Total amount of Se Met-Free amount of SeMet }}{\text { Total amount of SeMet }} \times 100$

\subsection{MTS assay}

The potential cytotoxicity of pure SeMet, SeMet loaded NPs and unloaded NPs (coated with zein) were examined on Caco-2 human epithelial cells, and HepG2 human liver hepatocellular cells. Both cell lines are routinely employed to assess the potential toxicity of orally delivered compounds (Brayden et al., 2015; Gleeson et al., 2015). Caco-2 and HepG2

cells, were seeded at a density of $2 \times 10^{4}$ cells/well and cultured on 96 well plates in (EMEM) respectively, supplemented with $10 \%$ foetal bovine serum, $1 \%$ L-glutamine, $1 \%$ penicillin-streptomycin and $1 \%$ non-essential amino acids at $37^{\circ} \mathrm{C}$ in a humidified incubator with $5 \% \mathrm{CO}_{2}$ and $95 \% \mathrm{O}_{2}$. Time points were selected with the intention to mimic in vivo conditions for each cell type. As the maximum time NPs will be exposed to the intestine, a 4 hr exposure time was used in Caco-2 cell lines (Neves et al., 2016), to mimic the liver, a 72h exposure time was used for HepG2 cell lines (Brayden et al., 2014). Triton X-100 $(0.05 \%)$ was used as a positive control. The concentrations of the test compounds applied were 25, 50 and $100 \mu \mathrm{M}$. After exposure, treatments were removed and replaced with MTS (3-(4,5-dimethylthiazol-2-yl)-5-(3-carboxymethoxyphenyl)-2-(4-sulfophenyl)-2Htetrazolium). Optical density (OD) was measured at $490 \mathrm{~nm}$ using a microplate reader

284 (TECAN GENios, Grodig, Austria). Each value presented was normalised against untreated control and calculated from three separate experiments, each of which included six replicates. 


\subsection{Accelerated stability analysis}

287 NPs were suspended at a concentration of $0.1 \mathrm{mg} / \mathrm{mL}$, in aqueous $\mathrm{KCl}$ solution $(10 \mathrm{mM})$ and stored at accelerated conditions; $60{ }^{\circ} \mathrm{C}$ for $720 \mathrm{~min}, 70{ }^{\circ} \mathrm{C}$ for $300 \mathrm{~min}$ and $80{ }^{\circ} \mathrm{C}$ for $120 \mathrm{~min}$ (Danish et al., 2017b). The particle size, PDI and ZP were measured using the Nanosizer ZS (Malvern Instruments Ltd, UK) over time intervals to determine the degree of degradation. The generated data was then analysed via R software (R Core Team, 2016). The temperature dependence of the kinetic parameters of SeMet-loaded NPs stability was measured by calculating the observed rate constants. This was plotted in an Arrhenius representation and apparent activation energy, $\mathrm{E}_{\mathrm{a}}$ and reaction rate constant, $\mathrm{k}_{\mathrm{ref}}$ were calculated according to $\mathrm{Eq}$. 3

$$
P=P o+e^{\ln (k)-\frac{E a}{R}\left(\frac{1}{T}-\frac{1}{T_{\text {ref }}}\right)} t
$$

where $\mathrm{P}$ is the property (particle size, PDI or $\mathrm{ZP}$ ) at time t, Po is the initial property conditions, $\mathrm{k}$ is the apparent zero order reaction constant, $\mathrm{E}_{\mathrm{a}}$ is the energy of activation, $\mathrm{R}$ is the universal gas constant, $\mathrm{T}$ is the temperature of the experiment in Kelvin $(\mathrm{K})$ and $\mathrm{T}_{\mathrm{ref}}$ is the reference temperature (343 K).

\subsection{In vitro controlled release studies}

302 SeMet release from the NPs was carried out using a dialysis bag diffusion technique 303 (Hosseinzadeh et al., 2012) over 6 hr (Calderon L. et al., 2013; Yoon et al., 2014). Freeze dried SeMet loaded NPs were suspended in $5 \mathrm{~mL} \mathrm{H}_{2} \mathrm{O}$ and sonicated at $35 \%$ amplitude for 30 s with 5 s intervals and placed into a Float-A-Lyzer ${ }^{\circledR}$ G2 dialysis membrane with a pore size of $25 \mathrm{kDa}$ (Spectrum Laboratories, USA). The sample was placed into $40 \mathrm{~mL}$ of

307 simulated gastric fluid (SGF) or simulated intestinal fluid (SIF) specified according to the 
was composed of 1 volume of $0.2 \mathrm{M}$ trisodium phosphate dodecahydrate and 3 volumes of 0.1 M HCL (adjusted to pH 6.8), without enzymes (British Pharmacopoeia Commission,

311 2016). Samples were placed in a thermostatic shaker at $37^{\circ} \mathrm{C}$ and agitated at $100 \mathrm{rpm}$. At

312 predetermined time points, $1 \mathrm{~mL}$ of release fluid was analysed and replaced with simulated

313 fluid to maintain sink conditions.

314

315

SeMet release was measured by RP-HPLC (section 2.7). Eq. (4) was used to determine the \%

316 drug release;

317

$$
\operatorname{Drug}_{\text {rel }} \%=\frac{C(t)}{C(l)} * 100
$$

where Drug $_{r e l}$ is the percentage of SeMet released, $C(l)$ represents the concentration of drug loaded and $\mathrm{C}(\mathrm{t})$ represents the amount of drug released at time t, respectively.

\section{RESUlts AND Discussion}

\subsection{Response Surface Modelling - Box Behnken design}

324 The observed values for all 15 experiments described by the BBD yielded minimum and

325 maximum values for Size $\left(\mathrm{Y}_{1}\right)(152,318 \mathrm{~nm})$, PDI $\left(\mathrm{Y}_{2}\right)(0.218,0.554), \mathrm{ZP}\left(\mathrm{Y}_{3}\right)(26.0,42.7$ $\mathrm{mV}$ ) and EE\% ( $\left.\mathrm{Y}_{4}\right)$ of, $(24.7,41.4 \%)$. The reduced models resulting from the analysis are presented in table 2 . Response $\mathrm{Y}_{1}$ showed no significant terms in the model, suggesting that there was no evidence in the sample population that could prove the association of the independent variables with particle size. This finding is unsurprising, as the NPs produced in this study fell within a narrow target region $(152,318 \mathrm{~nm})$ and the regions of interest chosen 
331 in this study (e.g. Cs:TPP 4:1-8:1, pH 3-5), to produce the Cs NPs, have been well

332 established for yielding particle sizes within 100-400 nm range (Hassani et al., 2015;

333 Mohammed et al., 2017; Sipoli et al., 2015).

334

335 Responses $\mathrm{Y}_{2}-\mathrm{Y}_{4}$ (PDI, ZP and EE\% respectively) all showed a curvature with regards to $\mathrm{X}_{1^{-}}$

$336 \mathrm{X}_{3}$, as quadratic or interactive effects of some independent variables were statistically

337 significant in all the models.

338 
Table 2: Coded variable estimated coefficients (Coef) with associated standard error (SE Coef.) and uncoded reduced regression equations for $\mathbf{Y}_{2}-\mathbf{Y}_{4}$.

\begin{tabular}{|c|c|c|c|c|c|c|c|c|}
\hline \multicolumn{3}{|l|}{$\mathrm{Y}_{2}$ (PDI) } & \multicolumn{3}{|l|}{$\mathbf{Y}_{3}(\mathrm{ZP})$} & \multicolumn{3}{|l|}{$Y_{4}(E E \%)$} \\
\hline Term & Coef & SE Coef & Term & Coef & SE Coef & Term & Coef & SE Coef \\
\hline Constant & 0.30833 & 0.00630 & Constant & 35.534 & 0.293 & Constant & 31.731 & 0.814 \\
\hline $\mathrm{X}_{1}(\mathrm{pH}-\mathrm{pI})$ & 0.05150 & 0.00386 & $\mathrm{X}_{1}(\mathrm{pH}-\mathrm{pI})$ & 6.405 & 0.300 & $\mathrm{X}_{1}(\mathrm{pH}-\mathrm{pI})$ & 6.113 & 0.599 \\
\hline $\begin{array}{l}\mathrm{X}_{2} \text { (SeMet } \\
(\mathrm{mg} / \mathrm{mL}))\end{array}$ & 0.00838 & 0.00386 & $\begin{array}{l}\mathrm{X}_{2}(\text { SeMet } \\
(\mathrm{mg} / \mathrm{mL}))\end{array}$ & - & - & $\begin{array}{l}\mathrm{X}_{2} \text { (SeMet } \\
(\mathrm{mg} / \mathrm{mL}))\end{array}$ & - & - \\
\hline $\begin{array}{l}\mathrm{X}_{3} \text { (Ratio } \\
\text { of Cs:TPP) }\end{array}$ & 0.05213 & 0.00386 & $\begin{array}{l}\mathrm{X}_{3} \text { (Ratio of } \\
\text { Cs:TPP) }\end{array}$ & 1.245 & 0.300 & $\begin{array}{l}\mathrm{X}_{3} \text { (Ratio of } \\
\text { Cs:TPP) }\end{array}$ & 0.487 & 0.599 \\
\hline $\mathrm{X}_{1} * \mathrm{X}_{1}$ & -0.06129 & 0.00568 & $\mathrm{X}_{1} * \mathrm{X}_{1}$ & ـ & - & $\mathrm{X}_{1} * \mathrm{X}_{1}$ & 3.821 & 0.879 \\
\hline $\mathrm{X}_{2} * \mathrm{X}_{2}$ & 0.10396 & 0.00568 & $\mathrm{X}_{2} * \mathrm{X}_{2}$ & - & - & $\mathrm{X}_{2} * \mathrm{X}_{2}$ & - & - \\
\hline $\mathrm{X}_{3} * \mathrm{X}_{3}$ & 0.06446 & 0.00568 & $\mathrm{X}_{3} * \mathrm{X}_{3}$ & -2.626 & 0.419 & $\mathrm{X}_{3} * \mathrm{X}_{3}$ & -3.529 & 0.879 \\
\hline $\mathrm{X}_{1} * \mathrm{X}_{2}$ & -0.01750 & 0.00545 & $\mathrm{X}_{1} * \mathrm{X}_{2}$ & - & - & $\mathrm{X}_{1} * \mathrm{X}_{2}$ & - & - \\
\hline$\overline{X_{1}} * X_{3}$ & 0.01650 & 0.00545 & $\mathrm{X}_{1} * \mathrm{X}_{3}$ & - & - & $\mathrm{X}_{1} * \mathrm{X}_{3}$ & - & - \\
\hline $\mathrm{X}_{2} * \mathrm{X}_{3}$ & -0.04025 & 0.00545 & $\mathrm{X}_{2} * \mathrm{X}_{3}$ & - & - & $\mathrm{X}_{2} * \mathrm{X}_{3}$ & - & - \\
\hline Lack of fit & \multicolumn{2}{|l|}{0.27} & Lack of fit & \multicolumn{2}{|l|}{0.09} & Lack of fit & \multicolumn{2}{|l|}{0.62} \\
\hline $\mathbf{R}^{2}$ adjusted & \multicolumn{2}{|l|}{ 98.66\% } & $\mathbf{R}^{2}$ adjusted & \multicolumn{2}{|l|}{$98.65 \%$} & $\mathbf{R}^{2}$ adjusted & \multicolumn{2}{|l|}{$90.82 \%$} \\
\hline Eq. (5) & \multicolumn{2}{|c|}{$\begin{array}{l}Y_{2}=0.592+0.212 X_{1} \\
-1.565 X_{2}-0.1495 X_{3}-0.06 \\
X_{1} * X_{1} \\
+10.40 X_{2} * X_{2}+0.01611 \\
X_{3} * X_{3}-0.175 X_{1} * X_{2}+0.00825 \\
X_{1} * X_{3}-0.2012 X_{2} * X_{3}\end{array}$} & Eq. (6) & \multicolumn{2}{|c|}{$\begin{array}{l}Y_{3}=-1.21+6.405 X_{1}+ \\
8.49 X_{3}-0.6588 X_{3} * X_{3}\end{array}$} & Eq. (7) & \multicolumn{2}{|c|}{$\begin{array}{l}Y_{4}=-2.06+5.35 X_{1}+ \\
10.83 X_{3}+3.821 X_{1} * X \\
-0.882 X_{3} * X_{3}\end{array}$} \\
\hline
\end{tabular}

341

342 In table 2 (Eq. 5), PDI was mostly affected by the quadratic effects of $\mathrm{X}_{2} * \mathrm{X}_{2}$, which showed

343 a positive correlation such that, at -1 and +1 levels of $\mathrm{X}_{2}$, the PDI increased. It is also worth

344 noting that the linear term of $\mathrm{X}_{2}$ showed a negative coefficient, indicating that $\mathrm{X}_{2}$ has a

345 negative effect on PDI until a turning point is reached, whereafter $\mathrm{X}_{2} * \mathrm{X}_{2}$ has a positive

346 impact on PDI. Similar findings were reported by Masarudin et al., (2015), who found that

347 ratios of Cs:TPP less than 3:1 and greater than 12:1, resulted in a significant increase of the

348 formed NPs PDI values ( $>0.75$ ). Additionally, they found that the NPs produced at ratios

349 between (median levels) the aformentioned upper and lower bounds resulted in NPs with PDI

350 values ranging from $0.15-0.32$. A contour plot based on the regression model is presented in

351 Figure 1(A) and highlights this, showing that, at medium load concentrations of $0.15 \mathrm{mg} / \mathrm{mL}$

352 and medium/low ratios of Cs:TPP (4.75:1 to 5.5:1), a minimum value for PDI can be

353 achieved. Conversely, as the concentration of TPP passes median levels PDI increases, which

354 may be attributable to TPP inducing cross-linking between the nanoparticles and thus the 
presence of smaller aggregates within the solution (Antoniou et al., 2015a; Hu et al., 2008). Furthermore, the reduction of PDI as the concentration of TPP approaches median levels, has been shown to relate with the increased availability of TPP molecules to interact with the free amino groups of chitosan, thus allowing for additional incorporation of the anion within the nanoparticle chitosan chains (Huang and Lapitsky, 2017). Although PDI can be minimised at these particular levels, it is worth noting that the PDI values for all formulations fell within optimum values for oral delivery (Wong et al., 2017).

The results presented in table 2 (Eq.6) show that $\mathrm{ZP}$ was not affected by $\mathrm{X}_{2}$, although it was affected by $\mathrm{X}_{1}(\mathrm{pH}-\mathrm{pI})$ and $\mathrm{X}_{3}(\mathrm{Cs}: \mathrm{TPP})$, indicating that the $\mathrm{pH}$ of the formulation medium and the electrostatic forces between the ionizable groups of Cs and TPP determine the net charge of the produced particles. It is likely that this is a direct consequence of the binding between the anionic phosphate groups of TPP with the positively charged amino acid moieties of Cs (Rampino et al., 2013), for example, a positive correlation was observed, such that ZP increased with increasing ratios. In addition, $\mathrm{X}_{1}$ also showed a prominent effect on $\mathrm{ZP}$, whereby an increase in $\mathrm{ZP}$ is observed as $\mathrm{X}_{1}$ increases. The contour plot representing the reduced regression model (Figure 1(B)), demonstrates that low $\mathrm{X}_{1}$ levels (pH 5 - 4.2) and low ratios of Cs:TPP (4.0/4.5:1) are the areas where NPs of $\mathrm{ZP}<30 \mathrm{mV}$ were obtained (with a minimum of $27 \mathrm{mV}$ ). As $\mathrm{X}_{1}$ increases (approximately $\mathrm{pH} 3.5$ ), an increment in ZP was observed and maximum values of $>39 \mathrm{mV}$ are achieved between $\mathrm{X}_{3}$ (ratio) of 4.5:1 - 7.5:1. This is in agreement with previous studies by Antoniou et al., (2015), that showed at Cs: TPP mass ratios of 7:1, the ZP of the produced NPs decreased almost linearly with increasing $\mathrm{pH}$ of the formulation medium. As it has been shown that high ZP (either negative or positive), requires higher energy for bringing two particles in contact with each other (Dora et al., 2010), this pH-responsive behaviour can be attributed to the protonation of the primary amino 
380

381

382

383

384

385

386

387

388

389

390

391

392

393

394

395

396

397

398

399

400

401

402

403

404

groups present on the Cs chain, resulting in an increase of electron density and repulsion forces between the crosslinked Cs chains (Lai and Guo, 2011). For example, at pH 3.5, the charge interaction between these two molecules becomes strong enough, and stable Cs NPs are obtained. On the contrary, at pH approaching the pI of Cs, reduced availability of protonated amine residues $\left(-\mathrm{NH}_{3}{ }^{+}\right)$present on the Cs polymer backbone chain results in a lower surface charge of the formed NPs (Huang et al., 2015).

EE\% was not affected by load concentration $\left(\mathrm{X}_{2}\right)$ but was mostly affected by the $\mathrm{pH}$ of the Cs media (pH-pI $\left(\mathrm{X}_{1}\right)$ ) (table 2 (Eq.7)), demonstrating the notable effect of SeMet loading with the charge of both polyelectrolytes (Cs and TPP) and their subsequent interaction during the crosslinking process. As can be seen, a negative correlation was observed, indicating that, as $\mathrm{X}_{1}$ increases, the EE\% decreases, most likely attributable to the reduced protonation of the primary amines present on Cs (Umerska et al., 2014). It is also worth noting that the quadratic term $\mathrm{X}_{1} * \mathrm{X}_{1}$ showed a positive coefficient, indicating $\mathrm{X}_{1}$ had a negative effect on EE\% until a turning point was reached, where after $\mathrm{X}_{1}$ had a positive impact on EE\%. He et al., (2017), reported that by exploiting the ionic nature of insulin through modulation of the formulation media, the EE\% of insulin into Cs:TPP NPs could be significantly enhanced, going from 37 to $94 \%$. This is evident in the contour plot produced by the regression model (Figure $1(\mathrm{C})$ ) showing that, at maximum $\mathrm{X}_{1}$ levels (approximately 2.5 unit distance from $\mathrm{pI}$ of SeMet) and minimum to median/high ratios of Cs:TPP (4:1 - 7.5:1), maximum EE \% (>40 \%) can be achieved, indicating that $\mathrm{pH}$ plays a significant role in the EE\%. These findings agree with those of other research groups (Antoniou et al., 2015b; Janes et al., 2001), that reported a strategy to increase ionisable proteins (such as bovine serum albumin (BSA) and insulin) EE\% (>80\%) within a Cs NP matrix, by dissolving the load protein at a $\mathrm{pH}$ above its isoelectric point. By doing this, deprotonation of the hydroxy groups present on the load 
cargo occurs, inducing a predominantly negative state and thus has a higher affinity to Cs and

406

407

408

409

410

411

412

413

414

415

416

417

418

419

420

421

422

423

424

425

426

427

428

429

430

increased EE\%. Several other studies have mirrored these findings, showing that the

electrostatic interactions between the acidic groups present on insulin and the amino groups

of Cs play a role in the association of insulin to the Cs-NPs by mediation of the ionic

interaction between both macromolecules (Mattu et al., 2013; Pan et al., 2002).

Figure 1: Contour Plot of (A) PDI against ratio of Cs:TPP $\left(X_{3}\right)$ and SeMet $(\mathrm{mg} / \mathrm{mL})$ $\left(\mathrm{X}_{2}\right)$, with $\mathrm{pH}-\mathrm{pI}\left(\mathrm{X}_{1}\right)$ held at median level (1.5), $(\mathrm{B}) \mathrm{ZP}$ against $\mathrm{pH}-\mathrm{pI}\left(\mathrm{X}_{1}\right)$ and the ratio of Cs:TPP $\left(\mathrm{X}_{3}\right)$ and $(\mathrm{C})$ EE\% against $\mathrm{pH}-\mathrm{pI}\left(\mathrm{X}_{1}\right)$ vs ratio of Cs:TPP $\left(\mathrm{X}_{3}\right)$ for the $\mathrm{RSM}$ models presented in Table 2.

\subsection{Optimisation}

Employing the models constructed with the BBD evaluation in Table 2, response optimisation was employed in order to establish a formulation strategy to yield NPs with minimum PDI values, $\mathrm{ZP}$ of $\geq 30 \mathrm{mV}$ and maximum EE\% (des Rieux et al., 2006). As the range of NP sizes within all experimental runs fell within recommended target values for oral delivery, this response was excluded from the optimisation analysis.

Figure 2 shows the optimisation plot of the desired responses and indicates that, when the variable settings of $\mathrm{X}_{1}, \mathrm{X}_{2}$ and $\mathrm{X}_{3}$ are fixed at $2.5(\mathrm{pH}-\mathrm{pI}), 0.15(\mathrm{mg} / \mathrm{mL})$ and 6 (Cs:TPP), respectively, NPs with the desired properties can be produced. Additionally, the $95 \%$ confidence interval ranges of the predicted NP properties that these conditions would produce are presented in Table 3.

Figure 2: Desirability profiles for optimisation of the formulation parameters; $\mathrm{X}_{1}(\mathrm{pH}-$ pI), $X_{2}$ (load concentration) and $X_{3}$ (Ratio of Cs:TPP) - maximising ZP and EE\%, whilst minimising PDI. 
Table 3: 95\% confidence interval for particle characteristics that optimal conditions would produce under the present experimental conditions of uncertainty

\begin{tabular}{|l|l|l|l|}
\hline Response & Fit & 95 \% CI & Actual values \\
\hline $\mathrm{Y}_{2}(\mathrm{PDI})$ & $0.299 \pm 0.007$ & $(0.282,0.317)$ & $0.284 \pm 0.044$ \\
\hline $\mathrm{Y}_{3}(\mathrm{mV})$ & $42.2 \pm 2.0$ & $(41.6,42.7)$ & $39.7 \pm 2.6$ \\
\hline $\mathrm{Y}_{4}(\mathrm{EE} \%)$ & $41.7 \pm 1.0$ & $(39.5,43.8)$ & $39 \pm 3$ \\
\hline
\end{tabular}

433

434 To verify the validity of the proposed models, $n=4$ replicates of the optimised formulation were prepared, and each experimental response was compared with the predicted one. Table 3 shows the validation results of the model, whereby NPs presented sizes of $187 \pm 58 \mathrm{~nm}$, PDI of $0.284 \pm 0.044$, ZP of $39.7 \pm 2.6 \mathrm{mV}$ and a max EE \% of $39 \pm 3 \%$. No statistical significant values $(\mathrm{p}>0.05)$ for predicted and measured responses $\left(\mathrm{Y}_{2}-\mathrm{Y}_{4}\right)$ were observed, indicating that the models fit the data satisfactorily and has adequate precision for the prediction of NP ZP, PDI and EE\% in the chosen space of independent variables (in the domain of levels chosen for the independent variables). Additionally, several consuming and laborious laboratory studies were eliminated in this study by using the BBD, rather than a OFAT approach.

\subsection{EE\% optimisation I: protonation and ionisation}

The results from the BBD were promising in terms of the NPs produced and their physicochemical properties. However, even when optimised, EE\% remained low at approximately $40 \%$. A second study was undertaken with the aim of maximising the EE\%, by controlling the ionisation process, given that this property primarily influenced the encapsulation efficiency in the desirability profile (Figure 2). In the previous BBD, it was noted that the highest EE\% of SeMet within Cs:TPP NPs was obtained when the pH of the Cs medium was maintained at $\mathrm{pH} 3$ and the SeMet load was dissolved within it prior to crosslinking. The fundamentals of ionotropic gelation exploit the opposing charges between 
the protonated amine residues found on the glucosamine residue unit of Cs against the deprotonated hydroxyl groups on TPP (Janes et al., 2001). In order to increase the EE\%, a

455

456

457

\subsection{Improved Encapsulation Efficiency using zein}

476 increase $\mathrm{EE} \% . \mathrm{N}=3$. encapsulation into the NP matrix.

modulation of the ionisation state of SeMet was achieved by dissolving it (and TPP) in a basic solution prior to crosslinking with Cs. The rationale for this approach is the observation that the pKa for the acid moiety of SeMet is $\mathrm{pH}$ 2.6, whereas the pKa for the basic moiety is at pH 8.9 (Foulkes, 2003) and as such, further electrostatic interactions can be induced at time of complexation (Qi et al., 2010). The effect of dissolving the TPP and SeMet in 0.01 M $\mathrm{NaOH}\left(\mathrm{pH}\right.$ 12) rather than $\mathrm{H}_{2} \mathrm{O}$ prior to crosslinking in the optimised formulation (ratio Cs:TPP 6:1, SeMet load concentration of $0.15 \mathrm{mg} / \mathrm{mL}$ and Cs medium $\mathrm{pH}$ of 3) was investigated, as a means to elicit greater interaction between Cs and SeMet and subsequently

By altering the $\mathrm{pH}$ of the formulation, the EE\% increased from $39 \pm 3 \%$ to $66 \pm 1 \%$, whilst the physicochemical properties of the NPs remained within the target range for oral delivery (Table 4) (des Rieux et al., 2006). This was most likely attributed to the electrostatic interactions between the now further ionised TPP and SeMet groups and protonated amine residues found on the glucosamine unit of Cs. This is consistent with the work by Pan et al., (2014) which showed curcumin (CUR) successful encapsulation (>90\%) into casein NPs, through deprotonation of CUR at $\mathrm{pH}$ 12, enabling for its re-association and thus subsequent

The results from the first EE\% optimisation study (Table 4) were promising, in terms of increasing EE\% in addition to maintaining the desired NP physicochemical properties. 
478 Nevertheless, the maximum EE\% obtained by modifying the $\mathrm{pH}$ remained at $66 \pm 4 \%$.

479 Therefore, a subsequent step, involving the coating of the optimised NPs with zein (at

480

481

482

483

484

485

486

487

488

489

490

491

492

493

494

495

496

497

498

499

500

501

502 varying zein:Cs mass ratios), was pursued as a means to increase the encapsulation efficiency of SeMet into the Cs: TPP NPs.

As shown in Table 4, as the ratio of zein in the formulation increased, the EE\% improved. At 0.5:1, zein:Cs, the average EE\% achieved was $75 \%$ and approximately $5 \%$ increments in EE\% were observed with subsequent increments of zein:Cs. The physicochemical properties of the NPs (PDI and ZP) were still within the target range for oral delivery for formulations with zein:Cs ratios $\leq 1: 1$, although an increase in NP size was observed upon increasing zein concentrations. At a ratio of 2:1, zein:Cs, the physicochemical properties of the NPs were less than ideal, as large particle sizes (721 nm average) and high PDI values (0.783) were yielded, most likely as a consequence of a denser and thicker coating (Luo et al., 2010) provided by the partial deposition of the negatively charged protein on the particle surface, thus reducing the total net charge and inducing particle swelling (Rampino et al., 2013). For example, as the zein concentration increases, so does the viscosity of the dispersion, which can affect the nucleation process leading to the production of larger sized NPs (Zhong and Jin, 2009). Similar results have been observed by others, whereby, an increase in zein concentration led to an increase in particle size of 6,7-dihydroxycoumarin loaded zein NPs (Podaralla and Perumal, 2012) or alpha-tocopherol loaded zein NPs, stabilised with Cs (Luo et al., 2012). Lastly, the ZP of this formulation was the lowest observed (average of $+6 \mathrm{mV}$ ), which may be attributed to the increasing zein concentration, causing increased masking of the free positively charged amino groups of Cs (Krauland and Alonso, 2007). It is also possible that agglomeration occurred as a result of the reduced electrostatic repulsion between the NPs in suspension (Liu and Gao, 2009). 
504 Table 4: Physiochemical results for SeMet loaded NPs (Ratio 6:1, SeMet in NaOH (0.15 $\mathrm{mg} / \mathrm{mL}$ load), Cs in pH 3) coated with zein. Size, PDI, ZP and EE\% are presented for each NP using different mass ratio combinations of zein and Cs. $\mathrm{N}=3$.

\begin{tabular}{|l|l|l|l|l|}
\hline Zein:Cs & Size $(\mathbf{n m})$ & PDI & ZP $(\mathbf{m V})$ & EE (\%) \\
\hline $0: 1$ & $227 \pm 17$ & $0.448 \pm 0.049$ & $32 \pm 1$ & $66 \pm 4$ \\
\hline $0.5: 1$ & $319 \pm 19$ & $0.221 \pm 0.040$ & $27 \pm 6$ & $74 \pm 1$ \\
\hline $1: 1$ & $377 \pm 47$ & $0.325 \pm 0.136$ & $35 \pm 6$ & $81 \pm 1$ \\
\hline $2: 1$ & $721 \pm 108$ & $0.783 \pm 0.281$ & $6 \pm 4$ & $85 \pm 1$ \\
\hline
\end{tabular}

\subsection{Characterisation of SeMet loaded and unloaded Cs:TPP NPs with and without} zein coating - Fourier transform infrared spectroscopy (FTIR)

Figure 3 shows the FTIR spectra of (A) zein, (B) TPP, (C) Cs, (D) SeMet:Cs:TPP NPs and

(E) SeMet:Cs:TPP:zein NPs. The zein spectrum (Figure 3, A) shows characteristic peaks at 3289, 2929, 1644, 1515 and $1233 \mathrm{~cm}^{-1}$ corresponding to; NH stretching vibrations, $\mathrm{CH}$ stretching, amide I ( $\mathrm{C}=\mathrm{O}$ stretch), amide II (C-N and $\mathrm{C}-\mathrm{N}-\mathrm{H} /$ in plane bending) and amide III respectively (Podaralla and Perumal, 2012). Characteristic peaks for the phosphate ion $(\mathrm{P}=\mathrm{O})$ in TPP (Figure 3, B) were observed at $1121 \mathrm{~cm}^{-1}$ and $886 \mathrm{~cm}^{-1}$, respectively (Rampino et al., 2013). Cs spectra (Figure 3, C) showed characteristic peaks at 3240, 2879, 1625, 1514, 1376 and $1063 \mathrm{~cm}^{-1}$. corresponding to NH Stretch / OH in pyranose ring, $\mathrm{CH}_{2}$ in $\mathrm{CH}_{2} \mathrm{OH}$ group, $\mathrm{C}=\mathrm{O}$ in $\mathrm{NHCOCH}_{3}$ group (amide I), $\mathrm{NH}_{2}$ in $\mathrm{NHCOCH}_{3}$ group (amide II), $\mathrm{CH}_{3}$ in $\mathrm{NHCOCH}_{3}$ group and C-O-C (glycosidic linkage) respectively (Luo et al., 2010; Mohammed et al., 2013). 
525 The FTIR spectrum of SeMet:Cs:TPP NPs (Figure 3, D) is different to that of the Cs matrix, 526 as a result of intermolecular interactions of the constituent components. If interaction

527 between the Cs and TPP had occurred, it will lead to frequency shifts or splitting in

528 absorption peaks (Gan et al., 2005). For example, the peaks at $1514 \mathrm{~cm}^{-1}$ in the Cs spectrum

529 have been shifted to $1560 \mathrm{~cm}^{-1}$, indicating electrostatic interaction between the phosphate

530 groups of TPP and the amino groups present in the Cs NP matrix (Papadimitriou et al., 2008).

531 Additionally, the broadening and the increased absorbance of the peak at $3272 \mathrm{~cm}^{-1}$ indicate hydrogen bonding has been enhanced (Luo et al., 2010). The band observed at $1644 \mathrm{~cm}^{-1}$ in

533 the zein FTIR spectrum (assigned to N-H bond), has been shifted to $1648 \mathrm{~cm}^{-1}$ in the zein/Cs

534 NPs spectrum (Figure 3, A and E respectively), indicating an interaction among the zein and

535 Cs chains, possibly through hydrogen bonding among the amino groups present on both Cs 536 and zein chains (Müller et al., 2011). Another indication of Cs:zein interaction arises from the amide III bands at $1406 \mathrm{~cm}^{-1}$, not visible in the zein spectrum, but now visible in the zein/Cs NPs (Figure 3, A and E respectively) spectrum, most likely as a result of the C-N stretching and out of plane N-H deformation being highly sensitive to structural changes (Sessa et al.,

540 2008).

542 Lastly, the formation of zein/Cs NPs (E) is also characterised by the appearance of a band at $5431041 \mathrm{~cm}^{-1}$ (assigned to C-O-C (glycosidic linkage)), which was observed in Cs/SeMet NPs

544 (D) at $1028 \mathrm{~cm}^{-1}$ but not observed in the zein spectrum (A), supporting the presence of Cs 545 within the NP matrix (Figure 3) (Müller et al., 2011). The crosslinked Cs also showed a peak 546 for $\mathrm{P}=\mathrm{O}$ at $1151 \mathrm{~cm}^{-1}$ (Bhumkar and Pokharkar, 2006), further indicating electrostatic

547 interaction between Cs and TPP (Figure 3, E). No significant SeMet peaks in either

$548 \mathrm{Cs} / \mathrm{TPP} / \mathrm{SeMet}$ or Cs/TPP/SeMet/zein NPs spectra were observed, most likely due to the fact, 
that only $0.07 \%$ of the dried formulation is contributed by SeMet and it is consequently masked by the other formulation components.

551

552

553

554

555

556

557

558

559

560

561

562

563

564

565

566

567

568

569

570

571

572

\subsection{Scanning electron microscopy}

Figure 4 shows the SEM images of uncoated and zein coated Se loaded NPs. The particle size of the NPs after spin coating was in good agreement with the DLS measurements taken on the freshly prepared NPs. Spherical, well distributed particles for both coated and uncoated SeMet loaded NPs were observed. However, it is interesting to note that the zein coated NPs displayed a smoother surface than that of the uncoated. This may be attributed to the use of the acetic acid buffer used during the formulation process, as similar results have been observed in spin-cast zein films prepared from an aqueous ethanol solvent compared to an acetic acid solution, indicating that a rough and hydrophilic surface was acquired for the former, whilst the zein film produced from an acetic acid solution appeared to be smooth, featureless and more hydrophobic (Shi et al., 2009; Y. Zhang et al., 2015).

\section{Figure 4: SEM image of (A) SeMet:Cs:TPP NPs and (B) SeMet:Cs:TPP NPs coated} with zein

\subsection{Accelerated stability analysis of SeMet-loaded NPs coated with zein}

The principle aim of accelerated stability testing is to provide reasonable assurance that a pharmaceutical or food consumable will remain at an acceptable level of quality throughout its timespan in the market place (Bajaj et al., 2012; Waterman and Adami, 2005). Real-time, retained sample, cyclic temperature and acceleration, are the four categories into which stability testing procedures fall (Bhagyashree et al., 2015). In the latter, the product is subjected to elevated temperatures and/or humidity well above ambient values, to determine the temperature at which product failure (i.e. degradation) will occur. 
574 The Arrhenius equation, upon which the interpretation of accelerated stability testing is

575 based, allows for the determination of the activation energy and consequently, the

576 degradation rate of a product at lower temperatures (i.e. ambient, refrigerated etc.). In this

577 instance, the data acquired can then be used to project the shelf life of the product in a much

578 shorter time than that of real time assessments (Ali et al., 2013; Bhagyashree et al., 2015).

579 This is a beneficial approach to stability testing, as it results in a greatly reduced product

580 development schedule.

581 Figure 5 shows the kinetic behaviour of the NP properties; size (A), PDI (B) and ZP (C) at

582 temperatures ranging from $60-80^{\circ} \mathrm{C}$. The stability of the NPs decreased with increasing

583 temperature. Little change was detected for all properties at $60{ }^{\circ} \mathrm{C}$, over the course of 720

584 min, whereas a more pronounced increment in size and PDI and a decrease in ZP was

585 observed at $70{ }^{\circ} \mathrm{C}$ after $300 \mathrm{~min}$. At $80^{\circ} \mathrm{C}$, destabilisation of the NP complexes was evident

586 across all properties, whereby size increased from approximately $300 \mathrm{~nm}$ to $>800 \mathrm{~nm}$, PDI

587 from approximately 0.2 to $>0.9$ and ZP reduced from approximately $32 \mathrm{mV}$ to $<18 \mathrm{mV}$,

588 indicating that aggregation of the NPs had occurred (Wu et al., 2011).

589

590 Figure 5: (1) Particle size, (2) PDI and (3) ZP analysis of SeMet loaded NPs exposed to

591 (a) $80{ }^{\circ} \mathrm{C}$, (b) $70^{\circ} \mathrm{C}$ and (c) $60^{\circ} \mathrm{C}$, over time periods of 120,300 and $720 \mathrm{~min}$,

592 respectively. $\mathrm{N}=3$

593 The one-step nonlinear regression analysis of the kinetic experiments shows that particle size

594 and PDI fit to a zero-order kinetic behaviour, with an Arrhenius dependence of ln $\left(\mathrm{k}_{\mathrm{ref}} @ 70\right.$

$\left.595{ }^{\circ} \mathrm{C}\right)=1.66 \pm 9.44 \mathrm{~min}^{-1}$ and $\mathrm{Ea}=452.57 \pm 570.59 \mathrm{~kJ} / \mathrm{mol}$ for size, and a $\ln \left(\mathrm{k}_{\text {ref }} @ 70{ }^{\circ} \mathrm{C}\right)=$

$5960.029 \pm 0.014 \mathrm{~min}^{-1}$, and an $\mathrm{Ea}=182.31 \pm 42.64 \mathrm{~kJ} / \mathrm{mol}$ for PDI respectively. In terms of ZP, 
an apparent first order mechanism fits the data better than that of an apparent zero order model, with an Arrhenius dependence of $\ln \left(\mathrm{k}_{\mathrm{ref}} @ 70{ }^{\circ} \mathrm{C}\right)=0.038 \pm 0.010 \mathrm{~min}^{-1}$ and $\mathrm{Ea}=$ $205.71 \pm 25.65 \mathrm{~kJ} / \mathrm{mol}$. Additionally, as can be seen in figure 6, a linear correlation is evident between $1 / \mathrm{T}$ and $\ln \mathrm{k}$, indicating that the formulations will be stable under normal storage conditions. This was expected, as previous reports have shown that zein coatings can increase the colloidal stability of iron phosphate NPs (Van Leeuwen et al., 2014) and, when stabilised with Cs, results in high thermal resistance of the NPs over prolonged periods of time (Luo et al., 2013).

\section{Figure 6: Arrhenius plots for the (A) ZP, (B) PDI and (C) size accelerated studies of}

\section{SeMet loaded NPs. $\mathbf{N}=3$.}

\subsection{Cytotoxicity assessment of SeMet-loaded NPs}

The potential cytotoxicity of SeMet in its native form and unloaded or SeMet loaded NPs coated with zein, at different test concentrations (25, 50 and $100 \mathrm{uM})$, were examined on Caco-2 human epithelial cells, and HepG2 human liver hepatocellular cells, using the MTS assay. As the NPs will become exposed to the intestinal epithelia following oral delivery (leading to its facilitated transport and uptake), time points were selected with the intention to mimic in vivo conditions for each cell type, to assess the potential cytotoxicity of the formulated NPs (Gleeson et al., 2015; Brayden et al., 2015). Caco-2 cells were exposed for 4h (figure 7(A)) and HepG2 cells for 72h (figure 7(B)). In Caco-2 exposures, no cytotoxicity was observed for unloaded or SeMet loaded NPs, in comparison to the negative control, across all tested concentrations. For HepG2 exposures, no cytotoxicity was observed for unloaded or SeMet loaded NPs coated with zein. Additionally, the lower concentrations (25 and $50 \mathrm{uM}$ ) of native SeMet showed no cytotoxicity to either cell line, whereas a reduction in 
621 HepG2 cell viability (figure 7(B)) for native SeMet, at the $100 \mu \mathrm{M}$ test concentration, was observed (approx. 66\% cell viability).

623

624 Similar results were observed by Takahashi, Suzuki and Ogra, 2017, whereby SeMet showed 625 no significant change on the viability of Caco-2 cell lines, although it did show marginal 626 toxicity to HepG2 cells at concentrations $>80 \mathrm{ug} / \mathrm{mL}$ after prolonged exposure (48 hr). This

627 finding is also in agreement with other works that showed SeMet toxicity occurred at 628 concentrations $\geq 40 \mathrm{uM}$ in various hepatoma cell lines (Kajander et al., 1991). It has previously been shown that Cs nanoparticles can enhance the delivery of inorganic Se compounds whilst reducing its toxicity (C. Zhang et al., 2015). In this work, SeMet loaded NPs elicited no significant reduction in viability of either cell line at equivalent concentration

632 (100 uM), indicating that, by encapsulating SeMet within the Cs NP matrix, the cytotoxic effects of pure SeMet, can be reduced.

634

635

Figure 7: Cytotoxicity assessment of $\square$ SeMet, $\square$ unloaded NPs with zein coating and

$\square$ SeMet loaded NPs with zein coating, exposed for (a) 4h in Caco-2 cell lines and (b) 72h

637 in HepG2 cell line at SeMet equivalent concentrations (25 uM, $50 \mathrm{uM}$ and $100 \mathrm{uM}$ ). Triton ${ }^{\mathrm{TM}}$

638 X-100 (0.05\%) was used as positive control and percentage (\%) of MTS converted was compared to untreated control. 1-Way ANOVA with Dunnetts’s post-test *** $\mathrm{P}<0.001$, ** $\mathrm{P}<0.01$, Each value presented was normalised against untreated control and calculated from

641 three separate experiments, each of which included six replicates. $\mathrm{N}=3$

642

643

\subsection{In vitro release studies}


645 In vitro techniques are advantageous for modelling potential interactions between NPs and

646 the in vivo environment of the GI tract. Simulated gastric fluid and membrane analysis

647 models enable assessment of in vivo environments without the use of human cell lines

648 (Gamboa and Leong, 2013). Figure 8, shows the cumulative release profile of SeMet loaded

649 NPs coated with zein, after subjection to $2 \mathrm{hr}$ in an SGF environment (pH 1.2) representative

650 of the stomach, followed by a compartmental change to SIF (pH 6.8), representative of the

651 intestine, for $4 \mathrm{hr}$. As can be seen, $25 \pm 1 \%$ of SeMet was released after $2 \mathrm{hr}$ in SGF, followed

652 by $33 \pm 3 \%$ in SIF for 4 hr. No significant difference in the release profile of SeMet loaded

653 NPs without zein coating was observed (data not shown). However, it was necessary to keep

654 zein in the formulation due to the increase in $\mathrm{EE}(\geq 80 \%)$.

655

656 The target site of absorption of SeMet is the jejunum, in the small intestine. Therefore, it is

657 important to withstand the acidic environment of the stomach. Three basic mechanisms that

658 are typically applied to describe the release of drugs from polymeric particles, are

659 swelling/erosion, diffusion, and degradation (Liechty et al., 2010). In this work, the total

660 cumulative release of SeMet from the zein coated NPs, after $6 \mathrm{hr}$ in simulated gastrointestinal

661 tract environments, was $58 \%$, indicating that degradation of the NP was slow and thus the

662 mechanism may be diffusion/relaxation oriented. As such, the release kinetics of SeMet NPs,

663 under the SGF and SIF sequential controlled release experiments, were fitted using the

664 following diffusive models derived from swellable systems (Siepmann and Peppas, 2011;

665 Danish et al., 2017a).

666

667

668

669 For the SGF: 


$$
\frac{M_{t}}{M_{\infty}}=k s_{1} *(\sqrt{\text { time }})+k s_{2} * \text { time }
$$

672 where $M_{t}$ is the diffused mass at a given time, $M_{\infty}$ is the asymptotic diffused mass at infinite

673 time, and $\mathrm{ks}_{1}$ and $\mathrm{ks}_{2}$ are the diffusive and relaxation rate constants respectively.

674

For the SIF:

676

$$
\frac{M_{t}}{M_{\infty}}-\frac{M_{120}}{M_{\infty}}=k i_{1} *(\sqrt{\text { time }-120})+k i_{2} *(\text { time }-120)
$$

678

where $\mathrm{M}_{120}$ is the predicted diffused mass at the time of changing from SGF to SIF (120 $\min ), \mathrm{ki}_{1}$ and $\mathrm{ki}_{2}$ are diffusive and relaxation rate constants.

681

Table 5: Swellable model parameters for kinetic release studies SeMet NPs. ks represents the stomach compartment and ki the intestinal compartment, divided into diffusion and relaxation mechanisms (1 and $\left.{ }_{2}\right)$. All parameters listed where statistically significant, ${ }^{* * *} \mathbf{P}<0.001 ;{ }^{*} \mathbf{P}<0.05$.

\begin{tabular}{|l|l|l|l|l|}
\hline Parameters & Estimate & Std. Error & t-value & Significance code \\
\hline $\mathrm{Ks}_{2}$ & 0.17082 & 0.04092 & 4.175 & $* * *$ \\
\hline $\mathrm{Ki}_{1}$ & 0.69145 & 0.33863 & 2.042 & $*$ \\
\hline $\mathrm{Ki}_{2}$ & 0.10817 & 0.02105 & 5.140 & $* * *$ \\
\hline $\mathbf{R}^{2}$ adj & & $\mathbf{0 . 9 8 4}$ & \\
\hline
\end{tabular}

687 Table 5 presents the fitted values for the rate constants in SGF (ks) and SIF (ki) for SeMet

688 NPs, with $\mathrm{ks}_{1}$, representing a diffusion mechanism and $\mathrm{ks}_{2}$ a relaxation mechanism (Eq. 8, 9).

689 In terms of the stomach compartment (SGF, pH 1.2), no statistically significant ks 1 parameter 690 was found, indicating that the primary mechanism for release in the stomach was via 
691 relaxation, i.e. slower release, approaching zero-order kinetics. After 2 hr subjected to the

692 SGF environment, a compartmental change was employed to mimic the movement of the

693 NPs to the intestinal environment (SIF, $\mathrm{pH}$ 6.8), whereupon a combination of diffusion ( $\left.\mathrm{ki}_{1}\right)$

694 and relaxation $\left(\mathrm{ki}_{2}\right)$ mechanisms were observed $(\mathrm{p}<0.05)$. Overall, the model employed (Eq.

695 8, 9) predicted the experimental data well, with an $\mathrm{R}^{2} \mathrm{adj}>0.98$. These results were expected,

696 as polysaccharides generally undergo solvent penetration, swelling and chain

697 disentanglement and relaxation, resulting in their ultimate dissolution (Fu and Kao, 2010).

698 Additionally, this result is in agreement with previous studies, reporting a diffusion and zero

699 order kinetic profile for IPP and LKP loaded CsNPs, coated with zein (Danish et al., 2017a)

700 and that of other researchers, who observed that zein proved to be a good coating for NPs,

701 whereby, the stronger the interaction of the load material (in this instance phenolic

702 monoterpenes) with that of the wall material (zein) was evidenced by its controlled release

703 over time (da Rosa et al., 2015).

704

705

Figure 8: Release kinetics of SeMet NPs coated with zein after 2 hr in SGF (pH 1.2) and

706

$4 \mathrm{hr}$ in SIF (pH 6.8).

707

708

4 CONCLUSION

709

In this study, SeMet-loaded Cs NPs were produced via ionotropic gelation. BBD was used to

710

identify optimum formulation variables that would result in NPs with physicochemical

711 properties thought to be suitable for oral delivery. BBD highlighted the optimum conditions

712 for NP production, although EE\% remained relatively low. By varying the formulation media

$713 \mathrm{pH}$, increased electrostatic interaction between the crosslinking polyelectrolytes and drug

714 were achieved, resulting in an increase in EE \%. Coating the NPs at a 1:1 mass ratio of

715 Cs:zein, resulted in NPs with a doubled EE accompanied by an increase in diameter. These 
716 NPs were then characterised via FTIR analysis, which identified the presence of key

717 functional groups of the native components and identifying shifts in the crosslinked matrixes.

718 SEM analysis showed that spherical, well distributed particles were observed. MTS

719 cytotoxicity studies showed no decrease in cellular viability in either Caco-2 or HepG2 cell

720 after 4 and 72 hr exposures, respectively. Accelerated thermal stability of the loaded NPs

721 indicated good stability under normal storage conditions. Lastly, after 6 hr exposure to

722 simulated intestinal buffers, the release profile of the formulation showed that $\leq 60 \%$ of the

723 drug had been released. These findings infer that encapsulation of SeMet into a NP delivery

724 system comprising food-derived components reveals an oral administration approach for this

725 molecule.

726

727 Funding:

728 This work was supported by Department of Agriculture, Food and Marine under FIRM (Food 729 Institutional Research Measure). Project Ref: 13F510.

730

731 Conflict of interest:

732 All authors have approved the final manuscript, and the authors declare that they have no conflicts of interest to disclose.

734

735

References:

736 Ali, M.S., Alam, M.S., Alam, N., Anwer, T., Safhi, M.M.A., 2013. Accelerated stability testing of a clobetasol propionate-loaded nanoemulsion as per ICH guidelines. Sci. Pharm. 81, 1089-1100. https://doi.org/10.3797/scipharm.1210-02

Amaro, M.I., Tewes, F., Gobbo, O., Tajber, L., Corrigan, O.I., Ehrhardt, C., Healy, A.M., 2015. Formulation, stability and pharmacokinetics of sugar-based salmon calcitonin- 
loaded nanoporous/nanoparticulate microparticles (NPMPs) for inhalation. Int. J. Pharm. 483, 6-18. https://doi.org/10.1016/j.ijpharm.2015.02.003

Anderson, M.J., Whitcomb, P.J., 2005. RSM simplified: optimizing processes using response surface methods for design of experiments. Productivity press.

Antoniou, J., Liu, F., Majeed, H., Qi, J., Yokoyama, W., Zhong, F., 2015a. Physicochemical and morphological properties of size-controlled chitosan-tripolyphosphate nanoparticles. Colloids Surfaces A Physicochem. Eng. Asp. 465, 137-146. https://doi.org/10.1016/j.colsurfa.2014.10.040

Antoniou, J., Liu, F., Majeed, H., Qi, J., Yokoyama, W., Zhong, F., 2015b. Physicochemical and morphological properties of size-controlled chitosan-tripolyphosphate nanoparticles. Colloids Surfaces A Physicochem. Eng. Asp. 465, 137-146.

752

753

754

755

756

757

758

759

760

761

762

763

764

765

Bajaj, S., Sakhuja, N., Singla, D., Bajaj Principal, S., 2012. Stability Testing of Pharmaceutical Products. J. Appl. Pharm. Sci. 02, 129-138. https://doi.org/10.7324/JAPS.2012.2322

Barrentine, L.B., 1999. An introduction to design of experiments: a simplified approach. ASQ Quality Press.

Benshitrit, R.C., Levi, C.S., Tal, S.L., Shimoni, E., Lesmes, U., 2012. Development of oral food-grade delivery systems: Current knowledge and future challenges. Food Funct. 3, 10. https://doi.org/10.1039/c1fo10068h

Bezerra, M.A., Santelli, R.E., Oliveira, E.P., Villar, L.S., Escaleira, L.A., 2008. Response surface methodology (RSM) as a tool for optimization in analytical chemistry. Talanta 76, 965-77. https://doi.org/10.1016/j.talanta.2008.05.019

Bhagyashree, P., Karishma, G., Sampada, A., Ankita, P., Pratibha, C., Kailash, V., 2015. Recent trends in stability testing of pharmaceutical products: A review. Res. J. Pharm. Biol. Chem. Sci. 6, 1557-1569. 
Bhumkar, D.R., Pokharkar, V.B., 2006. Studies on effect of pH on cross-linking of chitosan with sodium tripolyphosphate: a technical note. Aaps Pharmscitech 7, E138-E143.

Brayden, D.J., Cryan, S.-A., Dawson, K.A., O’Brien, P.J., Simpson, J.C., 2015. High-content analysis for drug delivery and nanoparticle applications. Drug Discov. Today 20, 942957. https://doi.org/10.1016/j.drudis.2015.04.001

Brayden, D.J., Gleeson, J., Walsh, E.G., 2014. A head-to-head multi-parametric high content analysis of a series of medium chain fatty acid intestinal permeation enhancers in Caco2 cells. Eur. J. Pharm. Biopharm. 88, 830-839.

British Pharmacopoeia Commission, 2016. British Pharmacopoeia: Appendix XII B. Dissolution. TSO, London.

Calderon L., Harris, R., Cordoba-Diaz, M., Elorza, M., Elorza, B., Lenoir, J., Adriaens, E., Remon, J.P., Heras, A., Cordoba-Diaz, D., 2013. Nano and microparticulate chitosanbased systems for antiviral topical delivery. Eur. J. Pharm. Sci. 48, 216-222. https://doi.org/10.1016/j.ejps.2012.11.002

Calvo, P., Remunan

f.Lopezlo@so, VMat.,Jato97. Novel hydrophilic chitosan $125-132$.

Chen, M.C., Mi, F.L., Liao, Z.X., Hsiao, C.W., Sonaje, K., Chung, M.F., Hsu, L.W., Sung, H.W., 2013. Recent advances in chitosan-based nanoparticles for oral delivery of macromolecules. Adv. Drug Deliv. Rev. https://doi.org/10.1016/j.addr.2012.10.010

Chintala, S., Najrana, T., Toth, K., Cao, S., Durrani, F. a, Pili, R., Rustum, Y.M., 2012. Prolyl hydroxylase 2 dependent and Von-Hippel-Lindau independent degradation of Hypoxiainducible factor 1 and 2 alpha by selenium in clear cell renal cell carcinoma leads to tumor growth inhibition. BMC Cancer 12, 293. https://doi.org/10.1186/1471-2407-12293 
814 Forootanfar, H., Adeli-Sardou, M., Nikkhoo, M., Mehrabani, M., Amir-Heidari, B., 815

da Rosa, C.G., de Oliveira Brisola Maciel, M.V., de Carvalho, S.M., de Melo, A.P.Z., Jummes, B., da Silva, T., Martelli, S.M., Villetti, M.A., Bertoldi, F.C., Barreto, P.L.M., 2015. Characterization and evaluation of physicochemical and antimicrobial properties of zein nanoparticles loaded with phenolics monoterpenes. Colloids Surfaces A Physicochem. Eng. Asp. 481, 337-344. https://doi.org/10.1016/j.colsurfa.2015.05.019

Danish, M.K., Vozza, G., Byrne, H.J., Frias, J.M., Ryan, S.M., 2017a. Comparative study of the structural and physicochemical properties of two food derived antihypertensive tripeptides, Isoleucine-Proline-Proline and Leucine-Lysine-Proline encapsulated into a chitosan based nanoparticle system. Innov. Food Sci. Emerg. Technol. https://doi.org/10.1016/j.ifset.2017.07.002

Danish, M.K., Vozza, G., Byrne, H.J., Frias, J.M., Ryan, S.M., 2017b. Formulation, Characterization and Stability Assessment of a Food-Derived Tripeptide, LeucineLysine-Proline Loaded Chitosan Nanoparticles. J. Food Sci. 82, 2094-2104. https://doi.org/10.1111/1750-3841.13824

Davies, M.J., 2016. Protein oxidation and peroxidation. Biochem. J. 473, 805-825.

des Rieux, A., Fievez, V., Garinot, M., Schneider, Y.-J., Préat, V., 2006. Nanoparticles as potential oral delivery systems of proteins and vaccines: a mechanistic approach. J. Control. release $116,1-27$.

Dora, C.P., Singh, S.K., Kumar, S., Datusalia, A.K., Deep, A., 2010. Development and characterization of nanoparticles of glibenclamide by solvent displacement method. Acta Pol. Pharm. - Drug Res. 67, 283-290.

Evans, S.O., Khairuddin, P.F., Jameson, M.B., 2017. Optimising Selenium for Modulation of Cancer Treatments. Anticancer Res. 37, 6497-6509. Shahverdi, A.R., Shakibaie, M., 2014. Antioxidant and cytotoxic effect of biologically 
synthesized selenium nanoparticles in comparison to selenium dioxide. J. Trace Elem. Med. Biol. 28, 75-79.

818

Foulkes, M.E., 2003. Screening Methods for Semi-quantitative Speciation Analysis. Handb. Elem. Speciat. Tech. Methodol. 591.

Fu, Y., Kao, W.J., 2010. Drug Release Kinetics and Transport Mechanisms of Nondegradable and Degradable Polymeric Delivery Systems. Expert Opin. Drug Deliv. 7,

Gamboa, J.M., Leong, K.W., 2013. In vitro and in vivo models for the study of oral delivery 824 of nanoparticles. Adv. Drug Deliv. Rev. 65, 800-810. https://doi.org/10.1016/j.addr.2013.01.003

Gan, Q., Wang, T., Cochrane, C., McCarron, P., 2005. Modulation of surface charge, particle 827 size and morphological properties of chitosan-TPP nanoparticles intended for gene delivery. Colloids Surfaces B Biointerfaces 44, 65-73.

Garousi, F., 2015. The toxicity of different selenium forms and compounds - Review. Acta Agrar. Debreceniensis 64, 33-38.

Gleeson, J.P., Heade, J., Ryan, S.M.M., Brayden, D.J., 2015. Stability, toxicity and intestinal permeation enhancement of two food-derived antihypertensive tripeptides, Ile-Pro-Pro and Leu-Lys-Pro. Peptides 71, 1-7. https://doi.org/10.1016/j.peptides.2015.05.009

Hassani, S., Laouini, A., Fessi, H., Charcosset, C., 2015. Preparation of chitosan-TPP nanoparticles using microengineered membranes-Effect of parameters and encapsulation of tacrine. Colloids Surfaces A Physicochem. Eng. Asp. 482, 34-43.

He, Z., Santos, J.L., Tian, H., Huang, H., Hu, Y., Liu, L., Leong, K.W., Chen, Y., Mao, H.Q., 2017. Scalable fabrication of size-controlled chitosan nanoparticles for oral delivery of insulin. Biomaterials 130, 28-41. https://doi.org/10.1016/j.biomaterials.2017.03.028

840 Helson, L., 2013. Curcumin (diferuloylmethane) delivery methods: A review. Biofactors 39, 
842 Hosseinzadeh, H., Atyabi, F., Dinarvand, R., Ostad, S.N., 2012. Chitosan-Pluronic 843 nanoparticles as oral delivery of anticancer gemcitabine: Preparation and in vitro study. Int. J. Nanomedicine 7, 1851-1863. https://doi.org/10.2147/IJN.S26365

Hu, B., Pan, C., Sun, Y., Hou, Z., Ye, H., Hu, B., Zeng, X., 2008. Optimization of fabrication parameters to produce chitosan- tripolyphosphate nanoparticles for delivery of tea catechins. J. Agric. Food Chem. 56, 7451-7458.

848

Huang, Y., Cai, Y., Lapitsky, Y., 2015. Factors affecting the stability of 849 chitosan/tripolyphosphate micro- and nanogels: resolving the opposing findings. J. Mater. Chem. B 3, 5957-5970. https://doi.org/10.1039/C5TB00431D

Huang, Y., Lapitsky, Y., 2017. On the kinetics of chitosan/tripolyphosphate micro- and 852 nanogel aggregation and their effects on particle polydispersity. J. Colloid Interface Sci. 486, 27-37. https://doi.org/10.1016/j.jcis.2016.09.050

854

855

856

Janes, K.A., Calvo, P., Alonso, M.J., 2001. Polysaccharide colloidal particles as delivery systems for macromolecules. Adv. Drug Deliv. Rev. 47, 83-97. https://doi.org/10.1016/S0169-409X(00)00123-X

857

Kajander, E.O., Harvima, R.J., Eloranta, T.O., Martikainen, H., Kantola, M., Kärenlampi, 858 S.O., Åkerman, K., 1991. Metabolism, cellular actions, and cytotoxicity of 860 selenomethionine in cultured cells. Biol. Trace Elem. Res. 28, 57-68. https://doi.org/10.1007/BF02990463

Krauland, A.H., Alonso, M.J., 2007. Chitosan/cyclodextrin nanoparticles as macromolecular 862 drug delivery system. Int. J. Pharm. 340, 134-142.

Lai, L.F., Guo, H.X., 2011. Preparation of new 5-fluorouracil-loaded zein nanoparticles for 864 liver targeting. Int. J. Pharm. 404, 317-323.

865 Liechty, W.B., Kryscio, D.R., Slaughter, B. V, Peppas, N.A., 2010. Polymers for Drug 
Delivery Systems. Annu. Rev. Chem. Biomol. Eng. 1, 149-173. https://doi.org/10.1146/annurev-chembioeng-073009-100847 nanoparticles. Polym. Adv. Technol. 20, 613-619.

870 Loeschner, K., Hadrup, N., Hansen, M., Pereira, S.A., Gammelgaard, B., Møller, L.H., 871 Mortensen, A., Lam, H.R., Larsen, E.H., 2014. Absorption, distribution, metabolism and excretion of selenium following oral administration of elemental selenium nanoparticles or selenite in rats. Metallomics 6, 330-337.

874 Luo, Y., Teng, Z., Wang, Q., 2012. Development of Zein Nanoparticles Coated with 875 Carboxymethyl Chitosan for Encapsulation and Controlled Release of Vitamin D3. J. Agric. Food Chem. 60, 836-843. https://doi.org/10.1021/jf204194z

Luo, Y., Wang, Q., 2014. Zein-based micro- and nano-particles for drug and nutrient 878 delivery: A review. J. Appl. Polym. Sci. 131, 1-12. https://doi.org/10.1002/app.40696 3-carbinol and 3,3'-diindolylmethane in zein/carboxymethyl chitosan nanoparticles with controlled release property and improved stability. Food Chem. 139, 224-230. https://doi.org/10.1016/j.foodchem.2013.01.113

Luo, Y., Zhang, B., Cheng, W.H., Wang, Q., 2010. Preparation, characterization and 884 evaluation of selenite-loaded chitosan/TPP nanoparticles with or without zein coating.

Maleki Dizaj, S., Lotfipour, F., Barzegar-Jalali, M., Zarrintan, M.-H., Adibkia, K., 2015. Box-Behnken experimental design for preparation and optimization of ciprofloxacin hydrochloride-loaded CaCO3 nanoparticles. J. Drug Deliv. Sci. Technol. 29, 125-131. https://doi.org/10.1016/j.jddst.2015.06.015 
891

892

893

894

895

896

897

898

899

900

901

902

903

904

905

906

907

908

909

910

911

912

913

914

915

determining the stability, size distribution, and cellular accumulation of small, monodisperse chitosan nanoparticles as candidate vectors for anticancer drug delivery: Application to the passive encapsulation of [14C]-doxorubicin. Nanotechnol. Sci. Appl. 8, 67-80. https://doi.org/10.2147/NSA.S91785

Mattu, C., Li, R., Ciardelli, G., 2013. Chitosan nanoparticles as therapeutic protein nanocarriers: The effect of ph on particle formation and encapsulation efficiency. Polym. Compos. 34, 1538-1545.

Mix, M., Ramnath, N., Gomez, J., de Groot, C., Rajan, S., Dibaj, S., Tan, W., Rustum, Y., Jameson, M.B., Singh, A.K., 2015. Effects of selenomethionine on acute toxicities from concurrent chemoradiation for inoperable stage III non-small cell lung cancer. World J. Clin. Oncol. 6, 156-165. https://doi.org/10.5306/wjco.v6.i5.156

Mohammed, M.A., Syeda, J.T.M., Wasan, K.M., Wasan, E.K., 2017. An overview of chitosan nanoparticles and its application in non-parenteral drug delivery. Pharmaceutics 9. https://doi.org/10.3390/pharmaceutics9040053

Mohammed, M.H., Williams, P. a., Tverezovskaya, O., 2013. Extraction of chitin from prawn shells and conversion to low molecular mass chitosan. Food Hydrocoll. 31, 166-171. https://doi.org/10.1016/j.foodhyd.2012.10.021

Mukhopadhyay, P., Sarkar, K., Chakraborty, M., Bhattacharya, S., Mishra, R., Kundu, P.P., 2013. Oral insulin delivery by self-assembled chitosan nanoparticles: in vitro and in vivo studies in diabetic animal model. Mater. Sci. Eng. C. Mater. Biol. Appl. 33, 376-82. https://doi.org/10.1016/j.msec.2012.09.001

Müller, V., Piai, J.F., Fajardo, A.R., Fávaro, S.L., Rubira, A.F., Muniz, E.C., 2011. Preparation and characterization of zein and zein-chitosan microspheres with great prospective of application in controlled drug release. J. Nanomater. 2011, 10.

Nagpal, K., Singh, S.K., Mishra, D.N., 2010. Chitosan Nanoparticles: A Promising System in 

https://doi.org/10.1248/cpb.58.1423

Nair, H.B., Sung, B., Yadav, V.R., Kannappan, R., Chaturvedi, M.M., Aggarwal, B.B., 2010. Delivery of antiinflammatory nutraceuticals by nanoparticles for the prevention and treatment of cancer. Biochem. Pharmacol. 80, 1833-43. https://doi.org/10.1016/j.bcp.2010.07.021

Narayan, V., Ravindra, K.C., Liao, C., Kaushal, N., Carlson, B.A., Prabhu, K.S., 2015. Epigenetic regulation of inflammatory gene expression in macrophages by selenium. J. Nutr. Biochem. 26, 138-145.

Neves, A.R., Martins, S., Segundo, M.A., Reis, S., 2016. Nanoscale delivery of resveratrol towards enhancement of supplements and nutraceuticals. Nutrients 8, 131.

Nie, T., Wu, H., Wong, K.-H., Chen, T., 2016. Facile synthesis of highly uniform selenium nanoparticles using glucose as the reductant and surface decorator to induce cancer cell apoptosis. J. Mater. Chem. B 4, 2351-2358.

Oberdörster, G., Maynard, A., Donaldson, K., Castranova, V., Fitzpatrick, J., Ausman, K., Carter, J., Karn, B., Kreyling, W., Lai, D., Olin, S., Monteiro-Riviere, N., Warheit, D., Yang, H., 2005. Principles for characterizing the potential human health effects from exposure to nanomaterials: elements of a screening strategy. Part. Fibre Toxicol. 2, 8.

Paliwal, R., Palakurthi, S., 2014. Zein in controlled drug delivery and tissue engineering. J. https://doi.org/10.1186/1743-8977-2-8

Pan, Y., Li, Y.J., Zhao, H.Y., Zheng, J.M., Xu, H., Wei, G., Hao, J.S., Cui, F. De, 2002. Bioadhesive polysaccharide in protein delivery system: Chitosan nanoparticles improve the intestinal absorption of insulin in vivo. Int. J. Pharm. 249, 139-147. https://doi.org/10.1016/S0378-5173(02)00486-6 
941 Panchuk, R.R., Skorokhyd, N.R., Kozak, Y.S., Lehka, L. V, Chumak, V. V, Omelyanchik, 942 S.N., Gurinovich, V.A., Moiseenok, A.G., Stoika, R.S., 2016. Antioxidants 943 selenomethionine and D-pantethine decrease the negative side effects of doxorubicin in 944 NL/Ly lymphoma-bearing mice. Croat. Med. J. 57, 180-92. $945 \quad$ https://doi.org/10.3325/cmj.2016.57.180

946 Papadimitriou, S., Bikiaris, D., Avgoustakis, K., Karavas, E., Georgarakis, M., 2008. 947 Chitosan nanoparticles loaded with dorzolamide and pramipexole. Carbohydr. Polym. 948 73, 44-54.

949 Pharmacopoeia, B., 2016. British Pharmacopoeia Commission: London.

950 Podaralla, S., Perumal, O., 2012. Influence of formulation factors on the preparation of zein $951 \quad$ nanoparticles. Aaps Pharmscitech 13, 919-927.

952 Qi, J., Yao, P., He, F., Yu, C., Huang, C., 2010. Nanoparticles with dextran/chitosan shell and 953 BSA/chitosan core-Doxorubicin loading and delivery. Int. J. Pharm. 393, 177-185. https://doi.org/10.1016/j.ijpharm.2010.03.063

Rampino, A., Borgogna, M., Blasi, P., Bellich, B., Cesàro, A., 2013. Chitosan nanoparticles: Preparation, size evolution and stability. Int. J. Pharm. 455, 219-228.

958

959

960

961

962

963

964

965 https://doi.org/https://doi.org/10.1016/j.ijpharm.2013.07.034

Rayman, M.P., 2000. The importance of selenium to human health. Lancet 356, 233-241. https://doi.org/10.1016/S0140-6736(00)02490-9

Rayman, M.P., Infante, H.G., Sargent, M., 2008. Food-chain selenium and human health: spotlight on speciation. Br. J. Nutr. 100, 238-253. https://doi.org/10.1017/S0007114508922522

Reddy, V.S., Bukke, S., Dutt, N., Rana, P., Pandey, A.K., 2017. A systematic review and meta-analysis of the circulatory, erythrocellular and CSF selenium levels in Alzheimer's disease: A metal meta-analysis (AMMA study-I). J. Trace Elem. Med. Biol. 42, 68-75. 
966 Reilly, K., Valverde, J., Finn, L., Gaffney, M., Rai, D.K., Brunton, N., 2014. A note on the 967 effectiveness of selenium supplementation of Irish-grown Allium crops. Irish J. Agric. $968 \quad$ Food Res. 91-99.

969 Ryan, K.B., Maher, S., Brayden, D.J., O’driscoll, C.M., 2012. .2: NANOSTRUCTURES OVERCOMING THE INTESTINAL BARRIER: DRUG DELIVERY STRATEGIES. Nanostructured Biomater. Overcoming Biol. Barriers 63.

Ryan, S.M., McMorrow, J., Umerska, A., Patel, H.B., Kornerup, K.N., Tajber, L., Murphy, E.P., Perretti, M., Corrigan, O.I., Brayden, D.J., 2013. An intra-articular salmon calcitonin-based nanocomplex reduces experimental inflammatory arthritis. J. Control. Release 167, 120-129.

976

Sessa, D.J., Mohamed, A., Byars, J.A., 2008. Chemistry and physical properties of melt977 processed and solution-cross-linked corn zein. J. Agric. Food Chem. 56, 7067-7075.

Shanmugam, M., Prakash, B., REDDY, E.P.K., PANDA, A.K., 2015. Dietary organic zinc 979 and selenium supplementation improves semen quality and fertility in layer breeders. Indian J. Anim. Sci. 85.

981

Shi, K., Kokini, J.L., Huang, Q., 2009. Engineering zein films with controlled surface 982 morphology and hydrophilicity. J. Agric. Food Chem. 57, 2186-2192. 983 https://doi.org/10.1021/jf803559v

984

Siepmann, J., Peppas, N.A., 2011. Higuchi equation: Derivation, applications, use and misuse. Int. J. Pharm. https://doi.org/10.1016/j.ijpharm.2011.03.051

Sipoli, C.C., Santana, N., Shimojo, A.A.M., Azzoni, A., de la Torre, L.G., 2015. Scalable 987 production of highly concentrated chitosan/TPP nanoparticles in different $\mathrm{pHs}$ and 988 evaluation of the in vitro transfection efficiency. Biochem. Eng. J. 94, 65-73. 
'Selenomethionine ameliorates cognitive decline, reduces tau hyperphosphorylation, and reverses synaptic deficit in the triple transgenic mouse model of alzheimer's disease', Journal of . J. Alzheimer’s Dis. 41, 85-99. https://doi.org/10.3233/JAD-131805

994

Takahashi, K., Suzuki, N., Ogra, Y., 2017. Bioavailability comparison of nine bioselenocompounds in vitro and in vivo. Int. J. Mol. Sci. 18, 1-11. https://doi.org/10.3390/ijms18030506

Traynor, M., Burke, R., Frias, J.M., Gaston, E., Barry-ryan, C., Traynor, M., Barry-ryan, C., 2013. Formation and Stability of an Oil in Water Emulsion Containing Lecithin , Xanthan Gum and Sunflower Oil Formation and Stability of an Oil in Water Emulsion Containing Lecithin , Xanthan Gum and Sunflower Oil 20, 2173-2181.

Umerska, A., Corrigan, O.I., Tajber, L., 2014. Intermolecular interactions between salmon calcitonin, hyaluronate, and chitosan and their impact on the process of formation and properties of peptide-loaded nanoparticles. Int. J. Pharm. 477, 102-112. https://doi.org/10.1016/j.ijpharm.2014.10.023

Van Leeuwen, Y.M.M., Velikov, K.P.P., Kegel, W.K.K., 2014. Colloidal stability and chemical reactivity of complex colloids containing Fe3+. Food Chem. 155, 161-166. https://doi.org/10.1016/j.foodchem.2014.01.045

Vongchan, P., Wutti-In, Y., Sajomsang, W., Gonil, P., Kothan, S., Linhardt, R.J., 2011. N, N, N-Trimethyl chitosan nanoparticles for the delivery of monoclonal antibodies against hepatocellular carcinoma cells. Carbohydr. Polym. 85, 215-220.

Wang, J.J., Zeng, Z.W., Xiao, R.Z., Xie, T., Zhou, G.L., Zhan, X.R., Wang, S.L., 2011. Recent advances of chitosan nanoparticles as drug carriers. Int. J. Nanomedicine. https://doi.org/10.2147/IJN.S17296

Wang, M., Wright, J., Buswell, R., Brownlee, A., 2013. A comparison of approaches to stepwise regression for global sensitivity analysis used with evolutionary optimization, 
in: Proceedings of the BS2013, 13th Conference of International Building Performance Simulation Association, Chambéry, France. pp. 26-28.

Ward, P., Connolly, C., Murphy, R., 2012. Accelerated Determination of Selenomethionine in Selenized Yeast: Validation of Analytical Method. Biol. Trace Elem. Res. 151, 446450. https://doi.org/10.1007/s12011-012-9571-x

Waterman, K.C., Adami, R.C., 2005. Accelerated aging: prediction of chemical stability of pharmaceuticals. Int. J. Pharm. 293, 101-125.

1023

Wong, C.Y., Al-Salami, H., Dass, C.R., 2017. The role of chitosan on oral delivery of peptide-loaded nanoparticle formulation. J. Drug Target. 0, 1-12. https://doi.org/10.1080/1061186X.2017.1400552

Wu, L., Zhang, J., Watanabe, W., 2011. Physical and chemical stability of drug nanoparticles. Adv. Drug Deliv. Rev. 63, 456-469.

Xu, H., Cao, W., Zhang, X., 2013. Selenium-containing polymers: promising biomaterials for controlled release and enzyme mimics. Acc. Chem. Res. 46, 1647-1658.

Yoon, H.Y., Son, S., Lee, S.J., You, D.G., Yhee, J.Y., Park, J.H., Swierczewska, M., Lee, S., Kwon, I.C., Kim, S.H., Kim, K., Pomper, M.G., 2014. Glycol chitosan nanoparticles as specialized cancer therapeutic vehicles: Sequential delivery of doxorubicin and Bcl-2 siRNA. Sci. Rep. 4, 6878. https://doi.org/10.1038/srep06878

Zhang, C., Zhai, X., Zhao, G., Ren, F., Leng, X., 2015. Synthesis, characterization, and

Zhang, H., Huang, Q., Huang, Z., Liu, T., Li, Y., 2015. Preparation and physicochemical properties of chitosan broadleaf holly leaf nanoparticles. Int. J. Pharm. 479, 212-218. https://doi.org/10.1016/j.ijpharm.2014.12.010 

chemopreventive agent with reduced risk of selenium toxicity: comparison with semethylselenocysteine in mice. Toxicol. Sci. 101, 22-31.

1043 Zhang, Y., Cui, L., Che, X., Zhang, H., Shi, N., Li, C., Chen, Y., Kong, W., 2015. Zein-based 1044 films and their usage for controlled delivery: Origin, classes and current landscape. J. 1045 Control. Release 206, 206-219. https://doi.org/10.1016/j.jconrel.2015.03.030

1046 Zhao, L., Zhu, B., Jia, Y., Hou, W., Su, C., 2013. Preparation of biocompatible 1047 carboxymethyl chitosan nanoparticles for delivery of antibiotic drug. Biomed Res. Int. 1048 2013, 1-8. https://doi.org/10.1155/2013/236469

1049 Zhong, Q., Jin, M., 2009. Zein nanoparticles produced by liquid-liquid dispersion. Food $1050 \quad$ Hydrocoll. 23, 2380-2387.

1051 Zolgharnein, J., Shahmoradi, A., Ghasemi, J.B., 2013. Comparative study of Box-Behnken, 1052 central composite, and Doehlert matrix for multivariate optimization of $\mathrm{Pb}$ (II) adsorption onto Robinia tree leaves. J. Chemom. 27, 12-20.

1054

1055 Graphical abstract: 


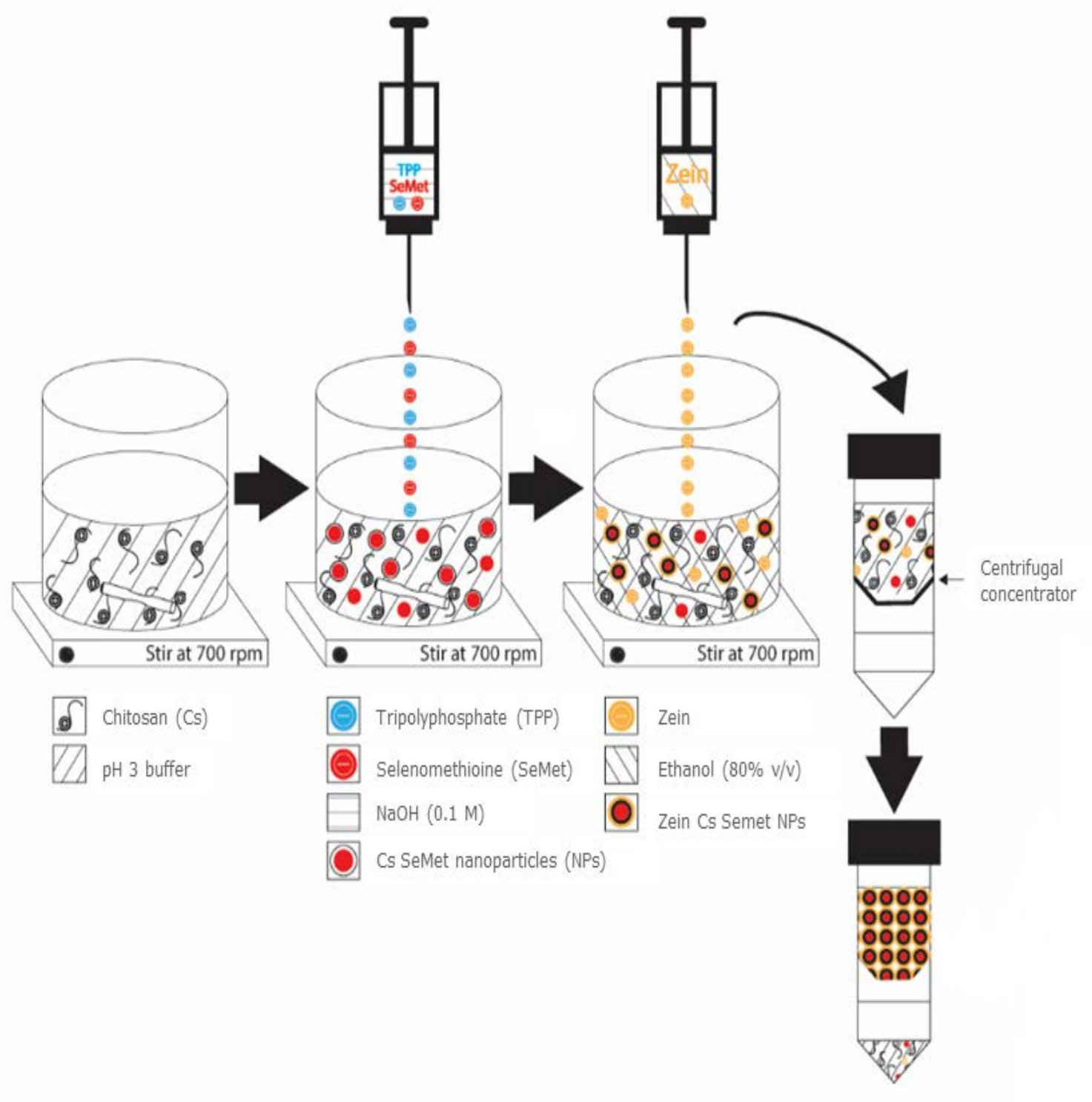

1057 The above graphic depicts the formulation methodology used to produce selenomethionine 1058 loaded chitosan nanoparticles, coated with zein, for in vitro assessment. Briefly, to produce 1059 the nanoparticles, chitosan was protonated by dissolving in acidic buffer ( $\mathrm{pH} 3$ ), then 1060 crosslinked with ionised tripolyphosphate and selenomethionine in $\mathrm{NaOH}(0.1 \mathrm{M})$. Zein 1061 coating was then employed to coat the nanoparticles and purification was achieved by removing unencapsulated formulation components through ultracentrifugation. 
1078

1079

1080

1081

1082

1083

1084

1085

1086

1087

1088

1089

1090

1091

of Cs:TPP $\left(\mathrm{X}_{3}\right)$ and $(\mathrm{C})$ EE\% against pH-pI $\left(\mathrm{X}_{1}\right)$ vs ratio of Cs:TPP $\left(\mathrm{X}_{3}\right)$ for the RSM models presented in Table 2.

Figure 2: Desirability profiles for optimisation of the formulation parameters; $\mathrm{X}_{1}(\mathrm{pH}-$ pI), $X_{2}$ (load concentration) and $X_{3}$ (Ratio of Cs:TPP) - maximising ZP and EE\%, whilst minimising PDI.

Figure 3: FTIR spectra of (A) zein, (B) TPP, (C) Cs, (D) SeMet:Cs:TPP NPs and (E) SeMet:Cs:TPP:zein NPs. Spectra are offset for clarity.

Figure 4: SEM image of (A) SeMet:Cs:TPP NPs and (B) SeMet:Cs:TPP NPs coated with zein

Figure 5: (1) Particle size, (2) PDI and (3) ZP analysis of SeMet loaded NPs exposed to (a) $80^{\circ} \mathrm{C}$, (b) $70^{\circ} \mathrm{C}$ and (c) $60^{\circ} \mathrm{C}$, over time periods of 120,300 and $720 \mathrm{~min}$, respectively. $\mathrm{N}=3$

Figure 6: Arrhenius plots for the (A) ZP, (B) PDI and (C) size accelerated studies of SeMet loaded NPs. $\mathrm{N}=3$.

Figure 7: Cytotoxicity assessment of $\square$ SeMet, $\square$ unloaded NPs with zein coating and $\square$ SeMet loaded NPs with zein coating, exposed for (a) 4h in Caco-2 cell lines and (b) 72h in HepG2 cell line at SeMet equivalent concentrations (25 uM, $50 \mathrm{uM}$ and $100 \mathrm{uM}$ ). Triton ${ }^{\mathrm{TM}}$ X-100 (0.05\%) was used as positive control and percentage (\%) of MTS converted was compared to untreated control. 1-Way ANOVA with Dunnetts's post-test $* * * \mathrm{P}<0.001$, ** $\mathrm{P}<0.01$, Each value presented was normalised against untreated control and calculated from three separate experiments, each of which included six replicates. $\mathrm{N}=3$ 
1092

1093 Figure 8: Release kinetics of SeMet NPs coated with zein after 2 hr in SGF (pH 1.2) and

$1094 \quad 4$ hr in SIF (pH 6.8).

1095

1096

1097
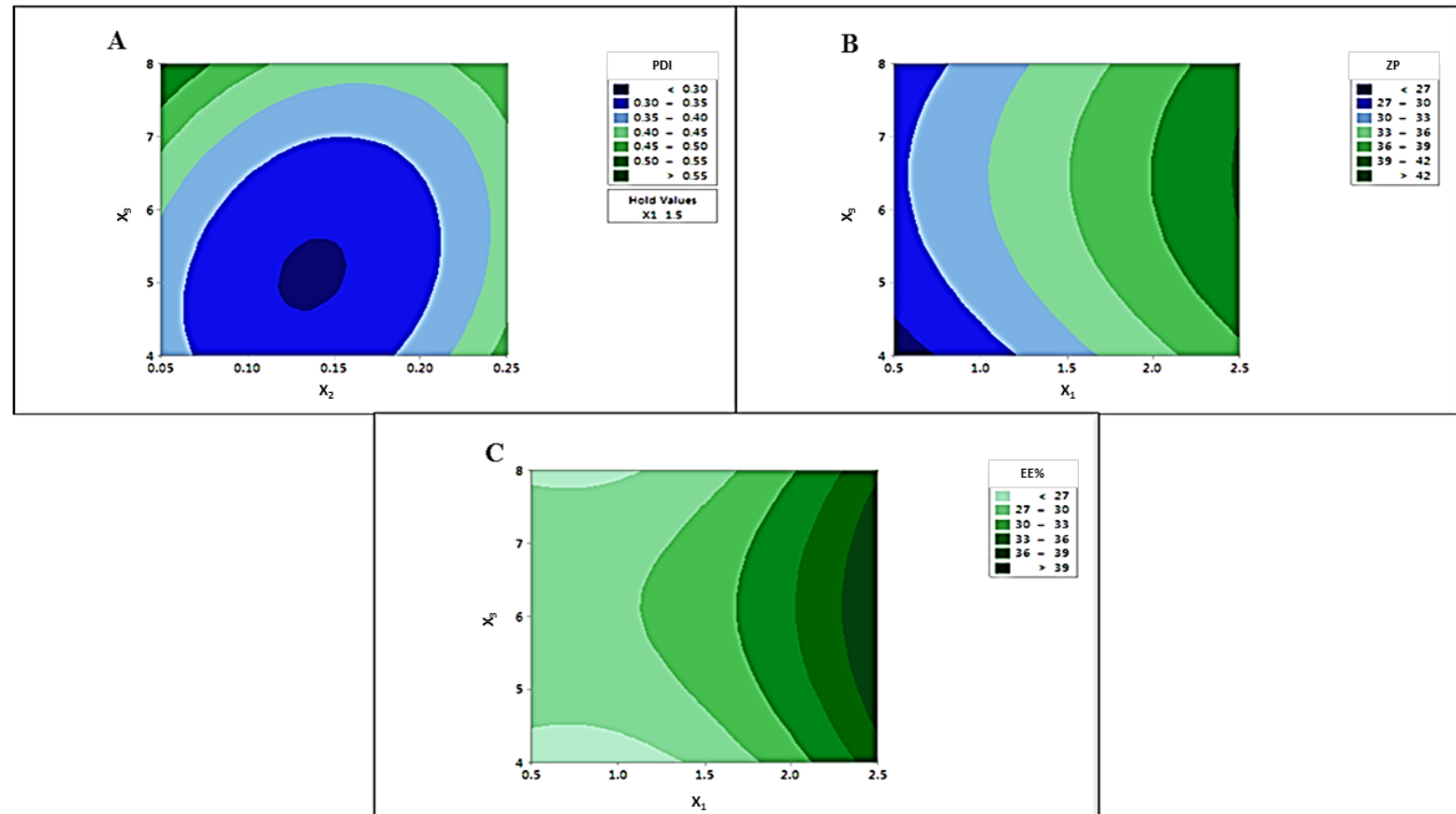

1098 Figure 1

1099 


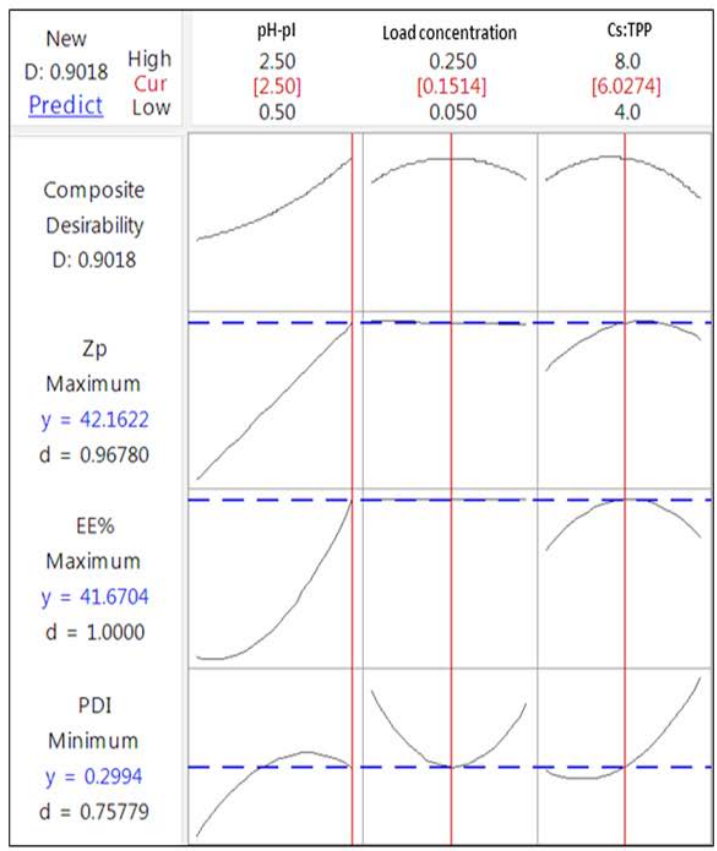

$1101 \quad$ Figure 2

1102

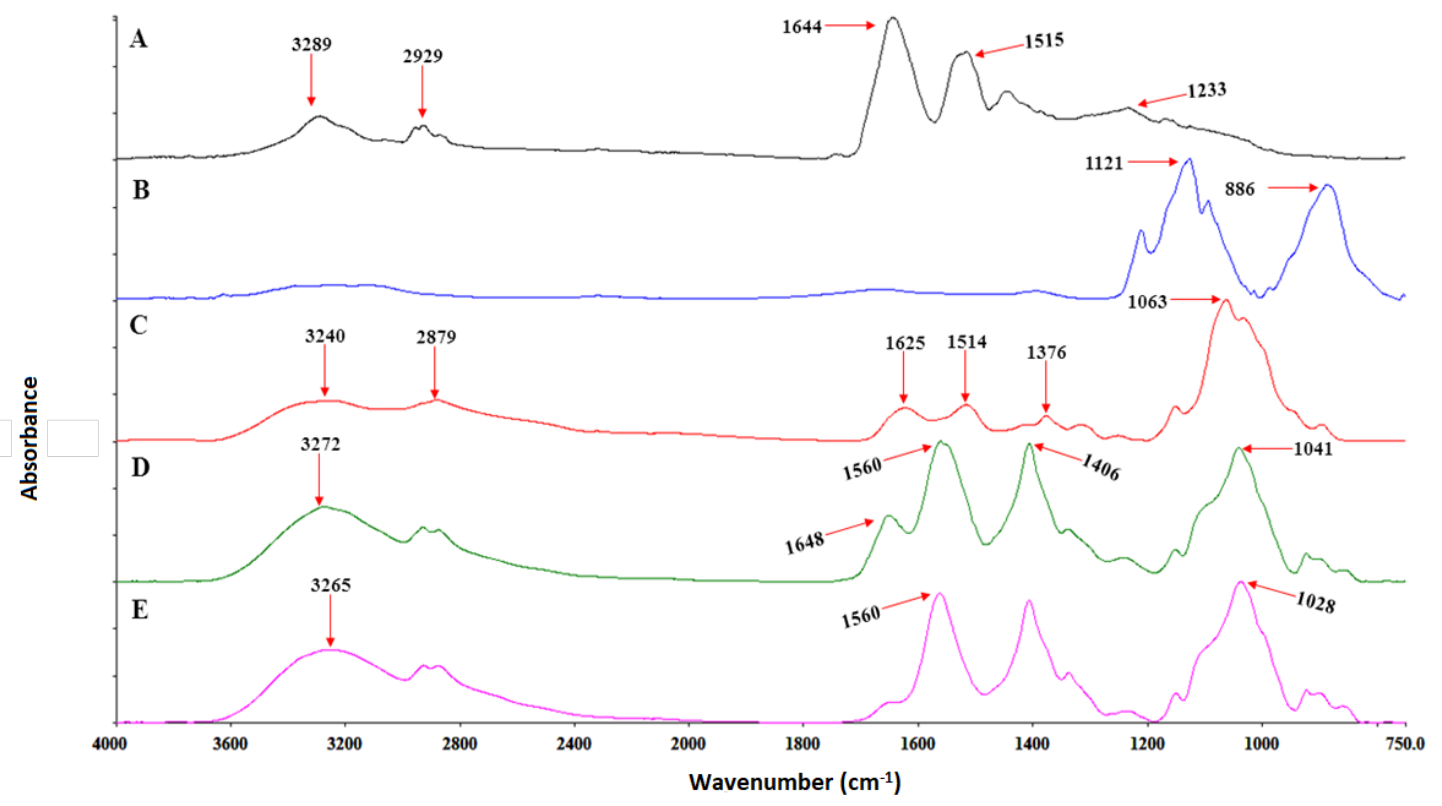

1103

$1104 \quad$ Figure 3

1105 

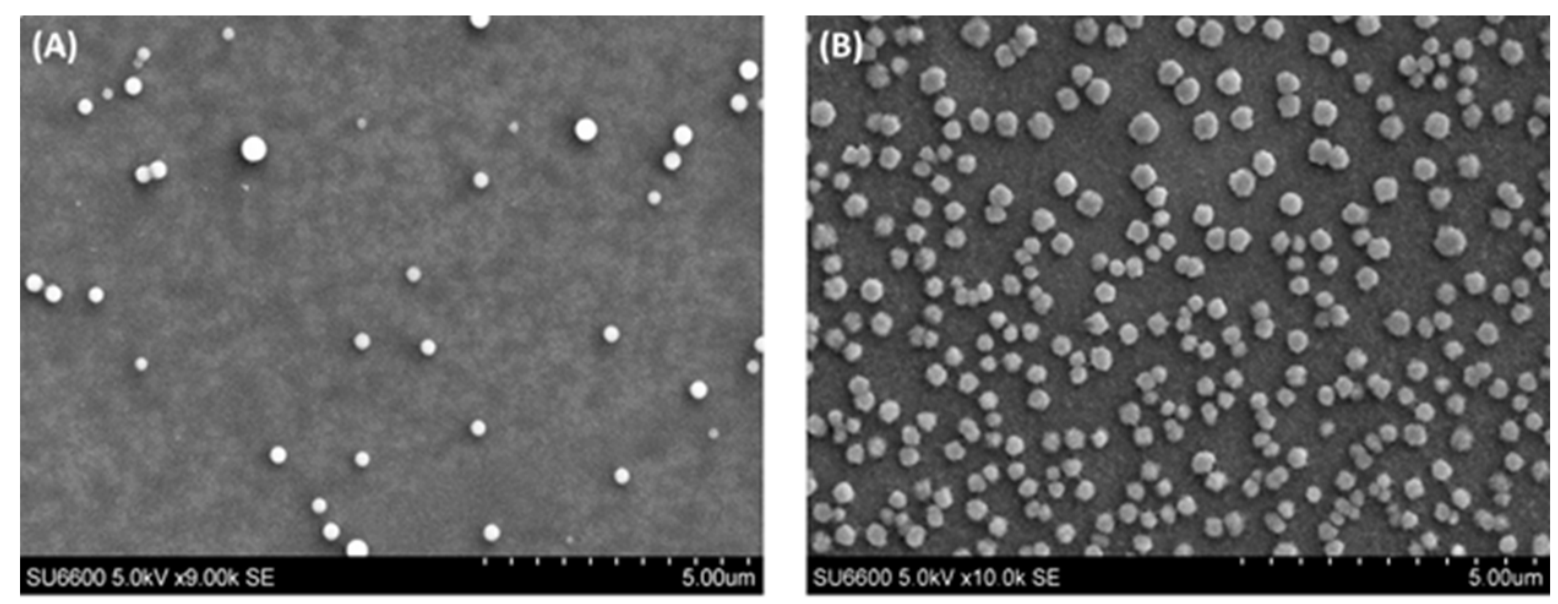

1106

$1107 \quad$ Figure 4

1108

(1)

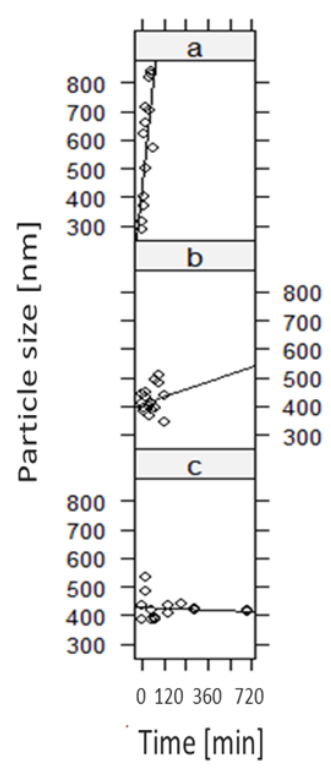

(2)

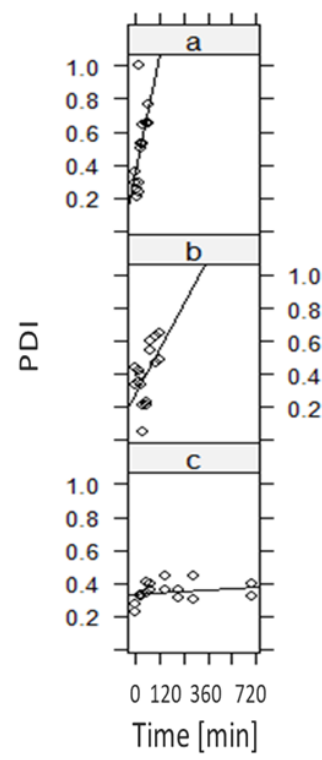

(3)

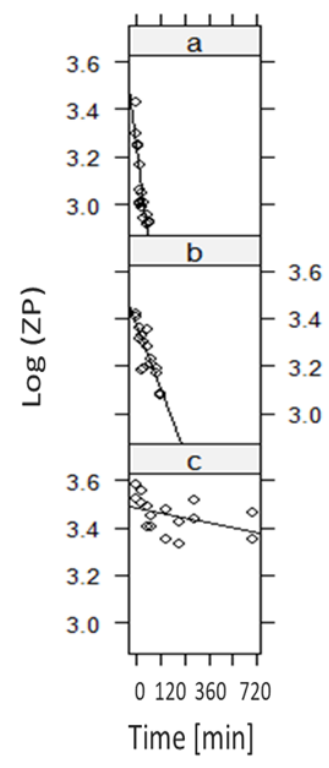

1109

$1110 \quad$ Figure 5

1111 

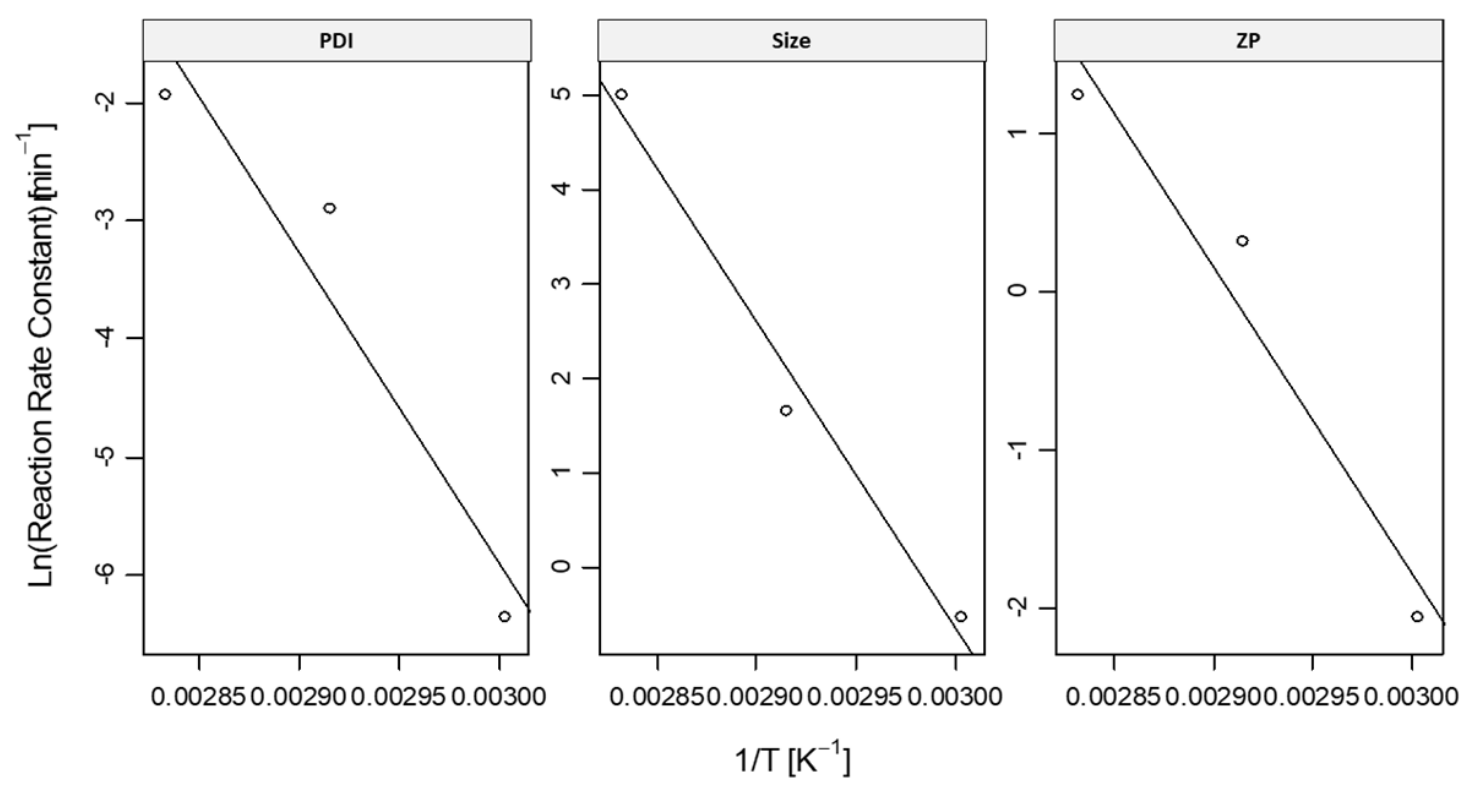

1112

\section{$1113 \quad$ Figure 6}

1114

(A)

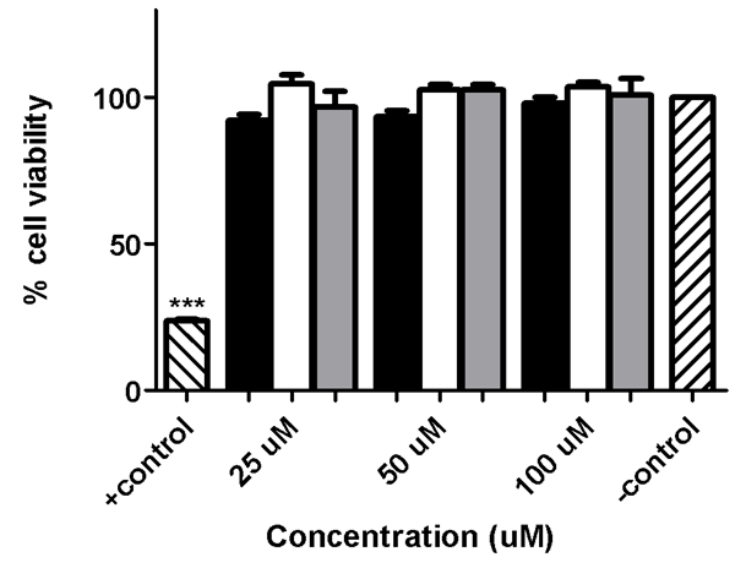

(B)

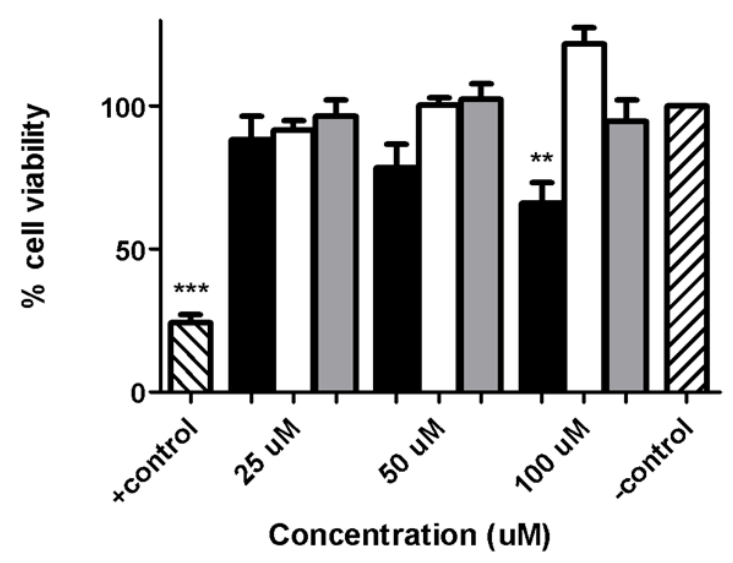

1115

\section{$1116 \quad$ Figure 7}

1117 


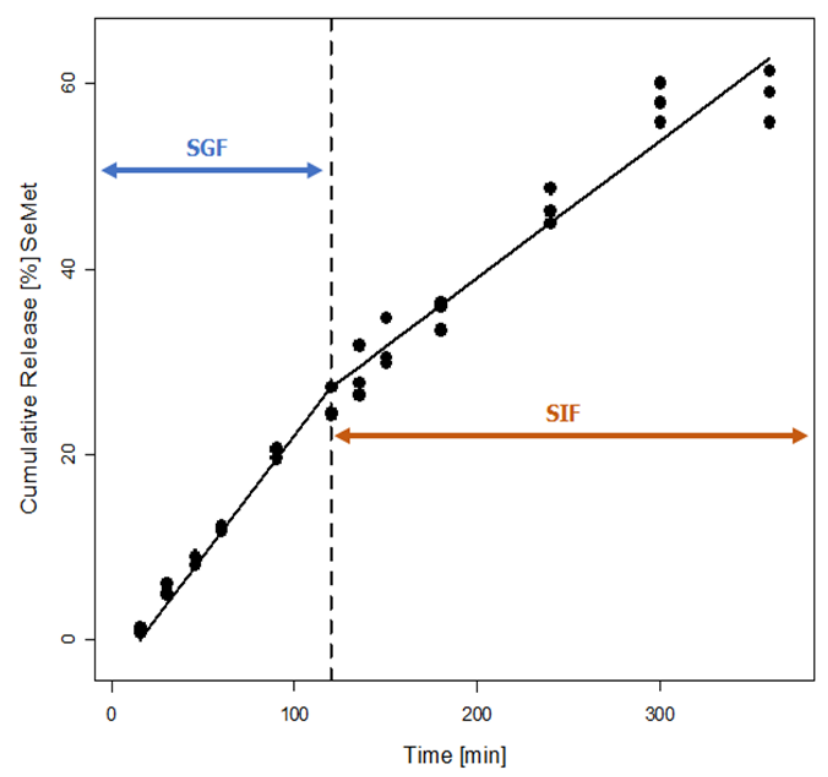

1118

$1119 \quad$ Figure 8 